\title{
Flow and sediment dynamics in channel confluences
}

\author{
M. Leite Ribeiro, ${ }^{1}$ K. Blanckaert, ${ }^{1,2}$ A. G. Roy, ${ }^{3}$ and A. J. Schleiss ${ }^{1}$ \\ Received 27 July 2011; revised 13 December 2011; accepted 19 December 2011; published 27 March 2012.
}

[1] Confluences with relatively low discharge and momentum flux ratios where a small steep tributary with a high supply of poorly sorted sediment joins a large, low-gradient main channel commonly occur in nature, but they have not yet been investigated. Measurements of the three-dimensional velocity field, turbulence, sediment transport, bed material grain size and morphology are reported in a laboratory setting that is representative of confluences on the Upper Rhone River, Switzerland. The difference between the low-flow depth in the steep tributary and the higher flow depth in the main channel creates a marked bed discordance in the tributary zone. Due to this bed discordance, the tributary flow penetrates into the main channel mainly in the upper part of the water column, whereas the main-channel flow is hardly hindered by the tributary in the lower part of the water column, giving rise to a two-layer flow structure in the confluence zone. In confluences with high supply of coarse sediment from the tributary, the development of a deposition bar downstream from the confluence reduces the flow area and causes flow acceleration that contributes to an increase in sediment transport capacity. The sediment supplied by the tributary is mainly sorted and transported on the face of the bar by the near-bed flow originating from the main channel. The sediment transport capacity is further increased by the three-dimensionality of the flow, which is characterized by maximum velocities occurring near the bed, and by a considerable increase in turbulent kinetic energy generated in the shear layer at the interface of the flows originating from the main channel and the tributary. A conceptual model is proposed for the hydro-morpho-sedimentary processes, and compared to existing conceptual models for confluences with different characteristics.

Citation: Leite Ribeiro, M., K. Blanckaert, A. G. Roy, and A. J. Schleiss (2012), Flow and sediment dynamics in channel confluences, J. Geophys. Res., 117, F01035, doi:10.1029/2011JF002171.

\section{Introduction}

[2] In fluvial networks, confluences are associated with significant changes in flow dynamics, sediment transport and bed morphology, which are known to depend on the confluence characteristics. Best [1987] investigated the flow dynamics at confluences in a small laboratory flume with two $0.15 \mathrm{~m}$ wide adjoining channels for several confluence angles and discharge ratios. Although these experiments were performed in a schematized configuration with fixed rectangular cross section, concordant beds (i.e., equal tributary and main channel bed elevations in the confluence zone) and without sediment transport, they revealed the dominant hydrodynamic processes occurring in a wide range of confluence configurations. Best [1987] proposed a conceptual

\footnotetext{
${ }^{1}$ Laboratory of Hydraulic Constructions, Ecole Polytechnique Fédérale de Lausanne, Lausanne, Switzerland.

${ }^{2}$ State Key Laboratory of Urban and Regional Ecology, Research Center for Eco-Environmental Sciences, Chinese Academy of Sciences, Beijing, China.

${ }^{3}$ Faculty of Environment, University of Waterloo, Waterloo, Ontario, Canada.

Copyright 2012 by the American Geophysical Union. 0148-0227/12/2011JF002171
}

model that distinguishes six hydrodynamic zones in confluence channels: flow deflection, flow stagnation, flow separation, maximum velocity, shear layer and flow recovery (Figure 1). The flow stagnation zone is created by a deflection of both streams at their junction and is associated with an increase of pressure and flow depth and a decrease of flow velocities and shear stresses. The directional change of the tributary creates a zone of flow separation with horizontal recirculation due to the flow detachment from the inner wall in the postconfluence channel and its reattachment further downstream [Best and Reid, 1984]. The geometry of the separation zone is important because it delimits the effective width of the postconfluence channel and is an area of reduced pressure and of recirculating flow, which promotes sediment accumulation. The maximum velocity zone appears downstream of the junction of the flows at the contracted cross section beside the separation zone. Shear layers are formed along the contact of the zones of flow separation and of maximum velocity, and they are characterized by high-turbulence intensities and shear stresses and also the presence of well-organized flow structures [Biron et al., 1993a; De Serres et al., 1999; Sukhodolov and Rhoads, 2001; Rhoads and Sukhodolov, 2004; Boyer et al., 2006]. As the shear layer expands laterally and dissipates, 


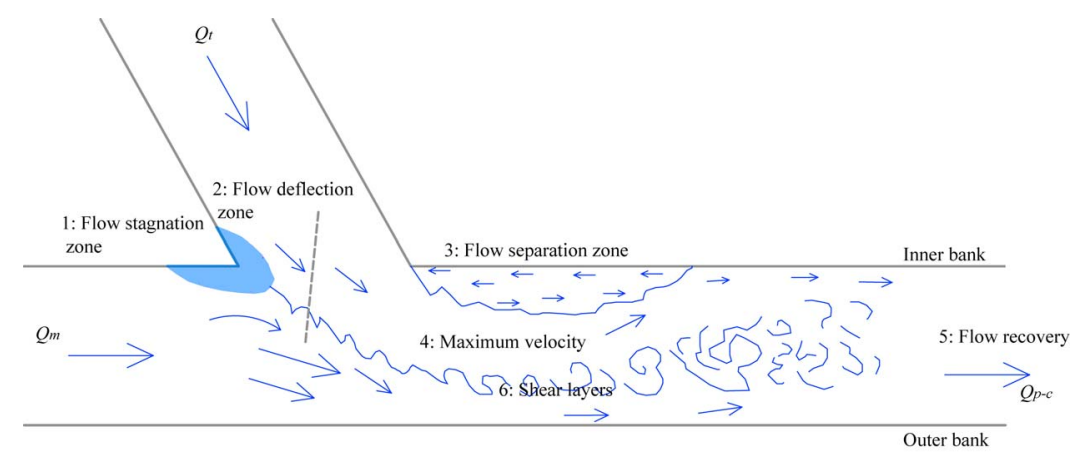

Figure 1. Descriptive model of flow dynamics at a channel confluence with horizontal concordant beds (slightly modified from Best [1987] with permission from Society for Sedimentary Geology).

the flow recovers toward a straight shear flow in the postconfluence channel.

[3] Flow at river confluences is three-dimensional and often characterized by the presence of helical flow cells. The nature and characteristics of these cells have been the subject of a long-standing debate [Mosley, 1976; Ashmore and Parker, 1983; Fujita and Komura, 1987; Rhoads and Kenworthy, 1995; McLelland et al., 1996; Bradbrook et al., 1998; Bradbrook et al., 2000a; Bradbrook et al., 2000b; Lane et al., 2000; Rhoads and Sukhodolov, 2001; Weber et al., 2001; Parsons et al., 2007; Biron and Lane, 2008]. The presence or absence of these cells, their number, and their intensity depend on the confluence characteristics.

[4] Processes occurring in alluvial river confluences are further complicated by the interaction between the flow, the sediment transport and the morphology. Table 1 summarizes the major previous investigations on the hydro-morphosedimentary processes in channel confluences (excluding confluences studied in braided environments), as well as their relevant characteristics. Table 1 reveals that the current understanding of channel confluences is based on a surprisingly small number of investigated configurations. Although these studies have provided valuable insight in the dynamics of confluence zones, they do not represent the full range of channel confluences encountered in nature that vary in, e.g., planform and slope of the confluent channels, confluence angle, discharge and momentum flux ratios, bed material and sediment supply. Best [1988], Boyer et al. [2006], and Rhoads et al. [2009], for example, proposed conceptual models for the hydro-morpho-sedimentary processes in a laboratory flume, the Bayonne-Berthier confluence, and the confluence of the Kaskaskia River and Copper Slough. The validity of these models is limited to confluence settings with similar characteristics.

[5] The principal objective of the present paper is to expand the understanding of the variety of influences on confluence morphodynamics, and to contribute to the formulation of a general process-response model by reporting on a laboratory investigation that extends the investigated parameter space to configurations that have the following characteristics (Table 1):

1. The main channel provides the dominant discharge, as quantified by the discharge and momentum flux ratios that are considerably lower than in the previous studies.

2 . The sediment is predominantly and abundantly supplied by the tributary, and consists of poorly sorted gravel with a high-gradation coefficient. Previous studies have included conditions where sediment supply by the tributary was dominant, but much less abundant than in the presently investigated configuration. Furthermore, these previous studies considered relatively well-sorted grains.

3. The tributary is smaller than the main channel, but is characterized by a relatively steep slope that is required to provide the dominant sediment transport. The flow in the tributary is transcritical during formative floods, i.e., the Froude number is close to unity. This contrasts with the previous studies, where both adjoining channels had similar dimensions, similar small longitudinal slopes, and a subcritical flow regime.

[6] Piedmont main channels that are joined by tributaries originating in lateral valleys are an example of this type of confluence. Such confluences are typically characterized by a pronounced difference between the bed elevations of the tributary and the main channel in the confluence zone, as illustrated by the example in Figure 2 .

[7] This so-called bed discordance is a typical feature of alluvial confluences [Kennedy, 1984]. It depends on the confluence characteristics, and especially on the flow ratio and the sediment supply, as will be discussed further in section 6.3. The confluence of the Kaskaskia River and the Copper Slough [Rhoads et al., 2009], for example, was characterized by conditions ranging from no bed discordance at low momentum ratio to mild bed discordance at high momentum ratio, whereas the Bayonne-Berthier confluence [Boyer et al., 2006] had moderate bed discordance. Bed discordance is an important morphological feature, which considerably affects the flow, the sediment transport and the morphology as indicated by field measurements [Biron et al., 1993b; Gaudet and Roy, 1995; De Serres et al., 1999], laboratory experiments [Best and Roy, 1991; Biron et al., 1996a], and numerical modeling [Bradbrook et al., 2001; Biron et al., 2004].

[8] Section 2 reports the design of the experimental setup and defines the characteristics of the investigated type of confluences. In sections 3 and 4 we observe, measure, quantify and discuss the morphologic, sediment transport and flow processes in the laboratory experiment. Section 5 discusses the representativeness of the results obtained in the schematized laboratory configuration. Section 6 proposes a conceptual model for the hydro-morpho-sedimentary processes in this type of confluence. Moreover, it contextualizes the results within the range of the foregoing 


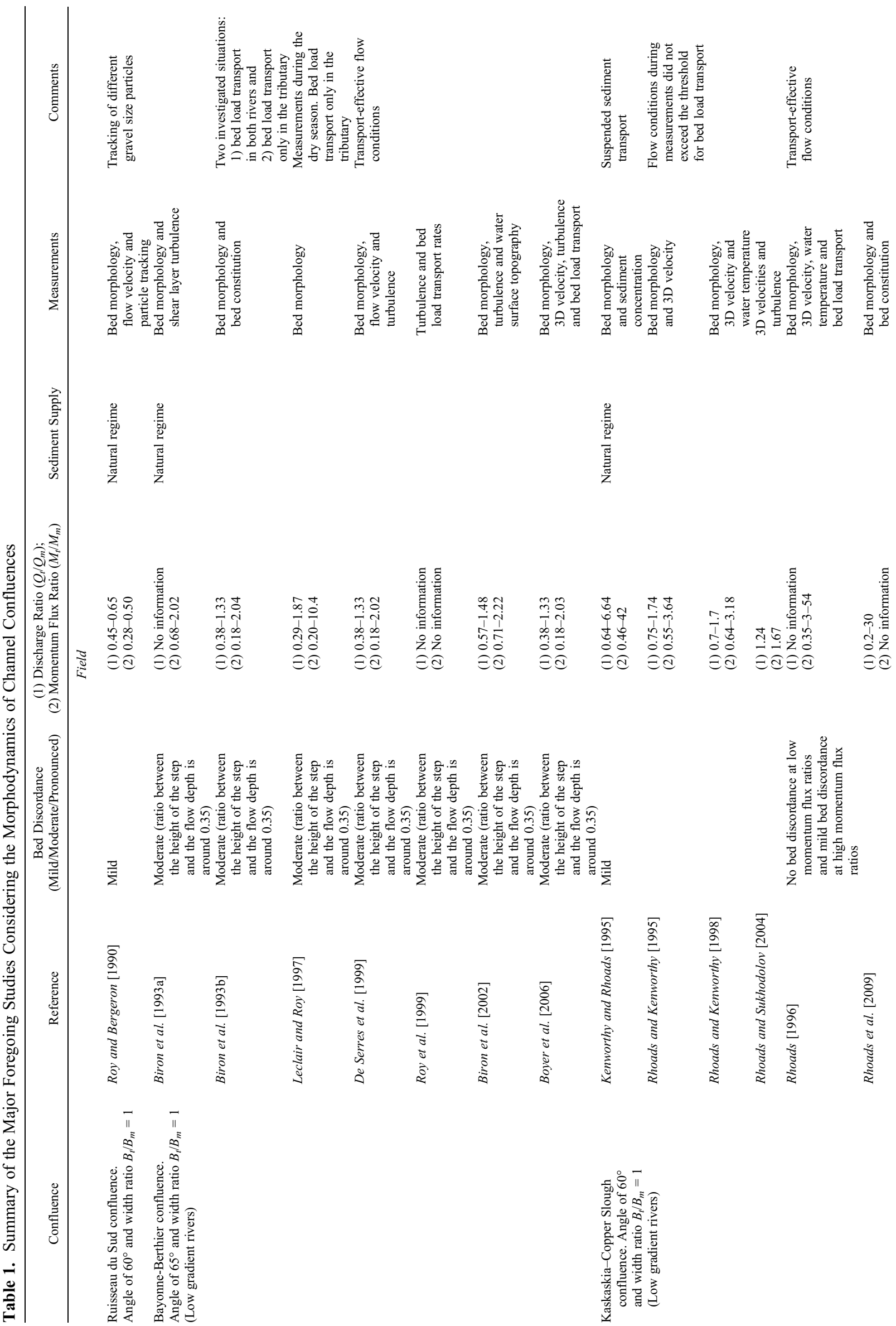




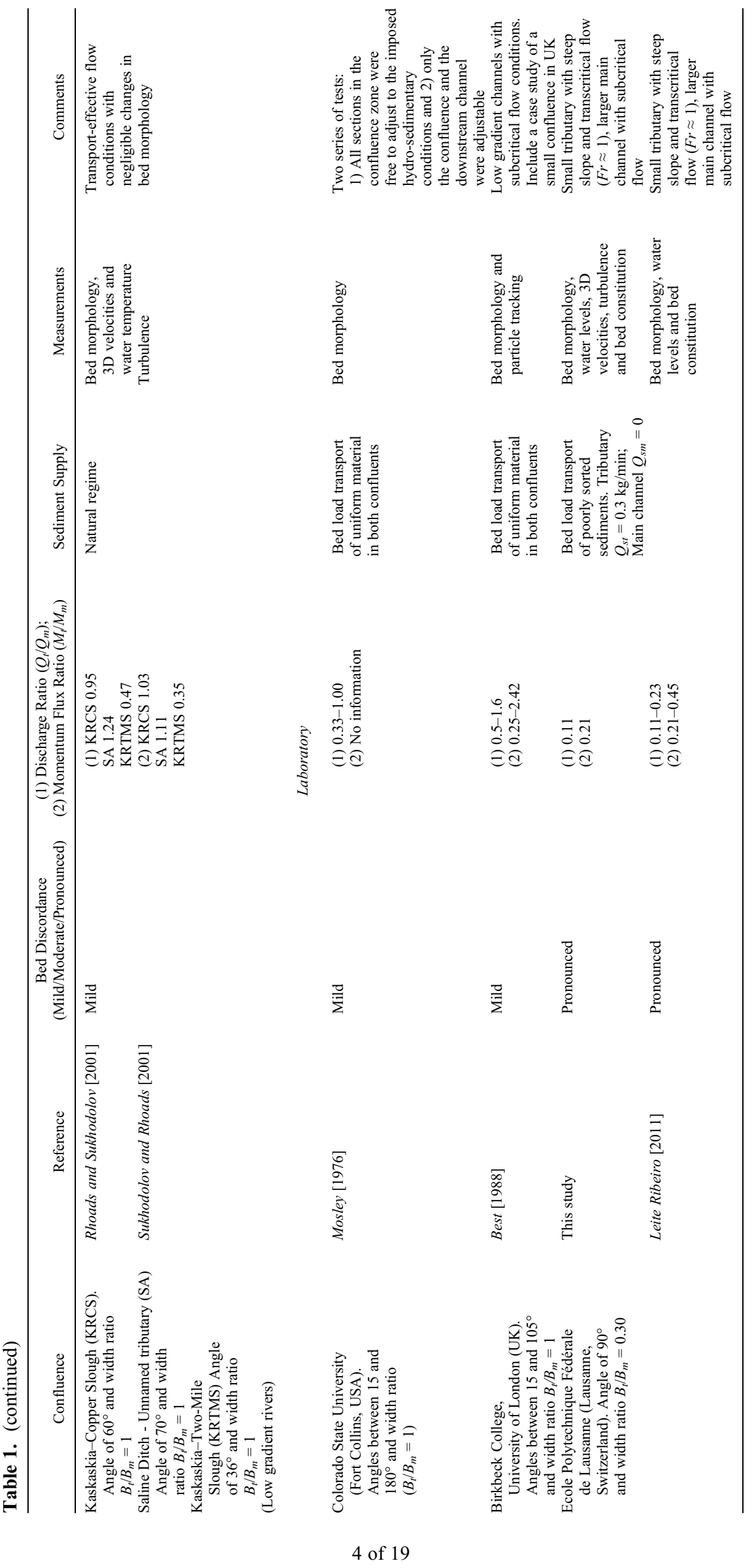




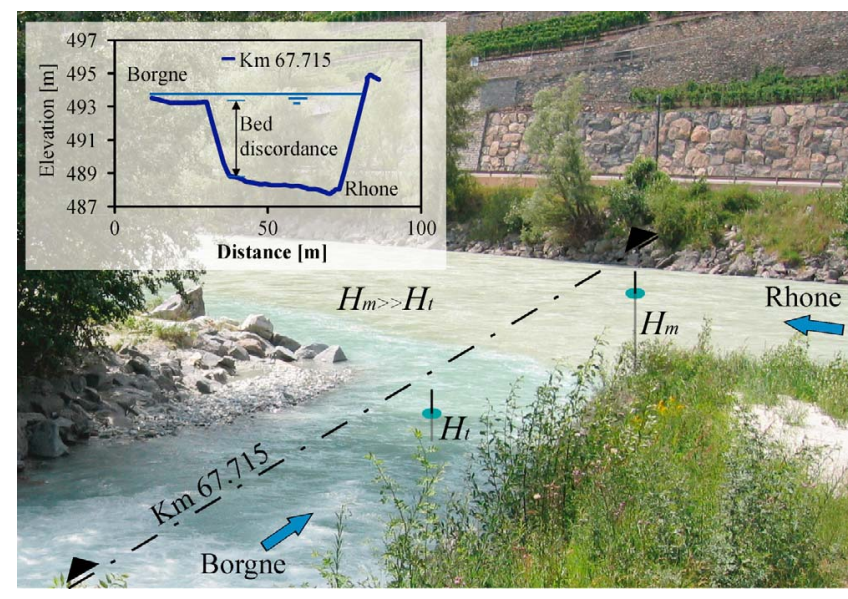

Figure 2. Confluence between the Upper Rhone River and the Borgne in Switzerland illustrating the important bed discordance. The confluence is located about $68 \mathrm{~km}$ upstream of Lake Geneva ( $\left.46^{\circ} 14^{\prime} 38^{\prime \prime} \mathrm{N} / 7^{\circ} 22^{\prime} 56^{\prime \prime} \mathrm{E}\right)$.

studies, by discussing similarities and differences in the observed processes.

\section{Experiment}

[9] The design of the reported experiment, including the confluence geometry, the sediment characteristics and the flow and sediment discharges, is inspired by the confluences on the heavily engineered Upper Rhone River upstream of Lake Geneva, Switzerland. The experimental setup is not a scale model of one particular confluence, however, but rather a schematized configuration that aims to reproduce the dominant hydro-morpho-sedimentary processes occurring in a broader range of configurations with the characteristics described in the introduction.

[10] A summary of the geometric as well as the discharge characteristics of the Upper Rhone's 20 main confluences is presented in Table 2, where $B$ is the channel width, $Q 2$ and $Q 5$ represent the 2 and 5 year return period floods (adopted as formative floods), respectively, and the subscripts $t, m$ and $p-c$ represent the tributary, main and postconfluence channels, respectively (Figure 3). The Froude numbers at the tributary $\left(F r_{t}\right)$ and the momentum flux ratios $\left(M_{r}\right)$ between the tributary and the main channels estimated for $Q 2$ and $Q 5$ are also shown in Table 2.

[11] The experimental facility consists of a confluence flume with smooth vertical banks where the main channel is $8.5 \mathrm{~m}$ long and $0.50 \mathrm{~m}$ wide. The $4.9 \mathrm{~m}$ long and $0.15 \mathrm{~m}$ wide tributary channel is connected at an angle of $90^{\circ}$ to the main channel $3.60 \mathrm{~m}$ downstream of the inlet (Figure 3). The results discussed in this paper are related to the reference axes $(X, Y, Z)$ represented in Figure 3.
[12] The intersection angles of the tributaries with the upper Rhone River are highly variable (Table 2). For the present project, the maximum value of $90^{\circ}$ has been adopted. The ratio of the tributary width to the main channel width of $B_{t} / B_{m}=0.3$ and of the main channel width to the postconfluence channel width of $B_{m} / B_{p-c}=1$ are representative of the confluences in the Upper Rhone River.

[13] Flow discharges in the main channel and the tributary were constant at $Q_{m}=181 \mathrm{~s}^{-1}$ and $Q_{t}=21 \mathrm{~s}^{-1}$, respectively, leading to a discharge ratio of $Q_{t} / Q_{m}=0.11$, width-todepth ratios in the main channel, the postconfluence channel and the tributary of 5,7 and 9, respectively (Table 3 ), and a momentum flux ratio of $M r=\rho Q U_{t} / \rho Q U_{m}=0.20$, where $\rho$ is the water density $\left[\mathrm{kg} \mathrm{m}^{-3}\right]$ and $U$ the mean velocity $\left[\mathrm{m} \mathrm{s}^{-1}\right]$.

[14] Flow was rough turbulent, $R e_{*}=u * k_{s} / \nu>70$, in the main, tributary and postconfluence channels. $R e *$ represents the particle Reynolds number, $u *$ the shear velocity $\left[\mathrm{m} \mathrm{s}^{-1}\right]$ defined as $u_{*}=\sqrt{g H E_{s}}$ where $H$ and $E_{s}$ are the average flow depth and the energy gradient, $k_{s}$ is the characteristic particle size $[\mathrm{m}]$ and $\nu$ is the kinematic viscosity $\left[\mathrm{m}^{2} \mathrm{~s}^{-1}\right]$.

[15] The sediment characteristics satisfy three requirements: (1) they yield a longitudinal slope in the tributary that is in the range of those presented in Table 2: (2) they yield a Froude number in the tributary that is close to unity; (3) their grain size sorting is representative of the Upper Rhone within the reach that encompasses the 20 main considered confluences [Leite Ribeiro, 2011, Figures 3-16]. Poorly sorted sediments with $d_{50}=0.8 \mathrm{~mm}, d_{m}=2.3 \mathrm{~mm} d_{90}=$ $5.7 \mathrm{~mm}$ and a sorting coefficient of $\sigma=0.5\left(d_{84} / d_{50}+\right.$ $\left.d_{50} / d_{16}\right)=4.15$, were used for the bed material and the solid discharge. The particle size distribution of the sediment is shown in Figure 3.

[16] A constant sediment discharge is only supplied to the tributary and there is no sediment supply to the main channel. This procedure aims at reproducing conditions where the main channel's bed is armoured (discussed further in the paper) and its banks are protected, and where floods in the steep tributary carry important loads of sediment. Such conditions are encountered in the Upper Rhone River.

[17] The bed was initially covered with the poorly sorted sediment mixture in the main channel and the tributary. Before the beginning of the run, the bed was flattened in the main and postconfluence channels and had an initial longitudinal slope of around $0.05 \%$ in the tributary. The steady flow discharges were provided to the main channel and the tributary, respectively, and a constant solid discharge of $0.3 \mathrm{~kg} / \mathrm{min}$ was fed to the tributary. An adjustable tailgate at the end of the postconfluence channel controlled the flow depth within the entire flume. The water level at the end of this channel was kept constant at $0.07 \mathrm{~m}$. During the experiment, sediment volumes entering and leaving the flume were weighed. Achievement of equilibrium was assessed on the

Table 2. Geometrical and Hydraulic Characteristics of the 20 Main Confluences of the Upper Rhone River in Switzerland

\begin{tabular}{|c|c|c|c|c|c|c|c|c|c|c|}
\hline & Angle (deg) & $B_{t} / B_{m}$ & $B_{m} / B_{p-c}$ & $\begin{array}{c}\text { Tributary Bed } \\
\text { Slope }(\%)\end{array}$ & $Q 2_{t} / Q 2_{m}$ & $Q 5_{t} / Q 5_{m}$ & $F r_{t Q 2}$ & $F r_{t Q 5}$ & $M r \_Q 2$ & $M r \_Q 5$ \\
\hline Average & 62 & 0.22 & 1.02 & $1.1 \%$ & 0.10 & 0.09 & 0.83 & 0.83 & 0.11 & 0.08 \\
\hline Max & 90 & 0.54 & 1.27 & $4.0 \%$ & 0.32 & 0.31 & 1.29 & 1.30 & 0.45 & 0.30 \\
\hline Min & 30 & 0.07 & 0.71 & $0.0 \%$ & 0.01 & 0.01 & 0.03 & 0.03 & 0.01 & 0.01 \\
\hline
\end{tabular}




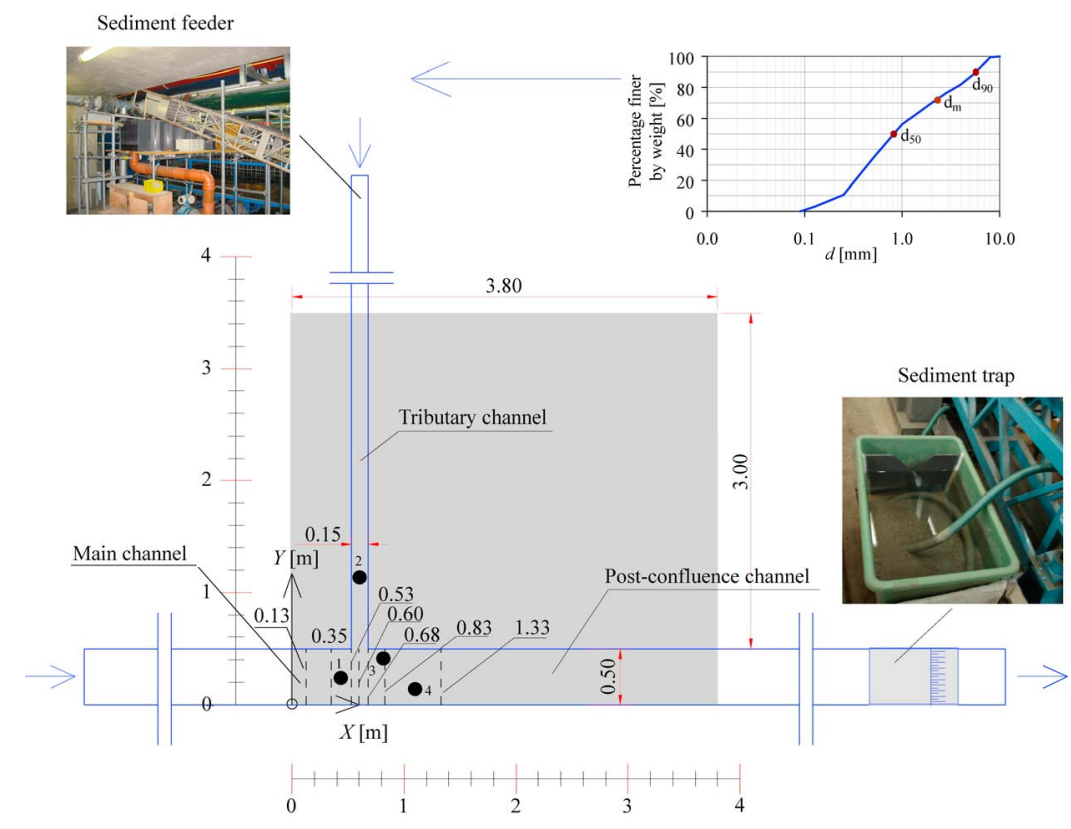

Figure 3. Experimental facility and sieving curve of the sediment. The locations of the cross sections where velocity measurements were performed are indicated by the dashed lines and the locations of the bed samples by the dark circles. The limit between the main channel and the postconfluence channel is the tributary axis at $\mathrm{X}=0.60 \mathrm{~m}$. In the grain size distribution curve, $d_{m}$ represents the mean particle diameter.

basis of changes in the bed morphology and of the sediment budget. Equilibrium conditions occurred $23 \mathrm{~h}$ after the beginning of the experiment.

[18] Water levels and bed topography were measured during the experiments with ultrasonic gauges and a Mini EchoSounder [Kantoush et al., 2008], respectively. Instruments were installed on a movable frame that covered a region of $3.80 \mathrm{~m}$ by $3.00 \mathrm{~m}$ in the confluence zone as shown in Figure 3. Upstream flow discharges were accurately measured by means of a calibrated $\mathrm{V}$ notch weir on the main channel and an electromagnetic flowmeter on the tributary channel, respectively. At the end of the experiment, samples of the surface bed material were collected at four different locations (S1, S2, S3, and S4 shown in Figure 3). Grain size analysis by means of hand sieving was carried out.

[19] Velocity measurements were performed over the mobile sediment bed once equilibrium conditions had been attained. Nonintrusive measurements of velocity profiles with an Acoustic Doppler Velocity Profiler (ADVP) developed at École Polytechnique Fédérale Lausanne (Switzerland) allowed visualizing the flow patterns with unprecedented detail. The working principle of the ADVP has been reported by Lemmin and Rolland [1997], Hurther and Lemmin [1998], Blanckaert and Graf [2001], and Blanckaert and Lemmin [2006]. The ADVP consists of a central emitter surrounded by four receivers, placed in a water filled box that touches the water surface by means of an acoustically transparent mylar film. It measures profiles of the quasi-instantaneous velocity vector, $\vec{u}(t)=\left(u_{x}(t), u_{y}(t), u_{z}(t)\right)$, from which the time-averaged velocity vector, $\vec{u}=u_{x}, u_{y}, u_{z}$, the Reynolds stresses, $-\rho \overrightarrow{u_{i}^{\prime} u_{i}^{\prime}}$ $(i, j=x, y, z)$ and higher-order turbulent correlations can be computed. Measurements were recorded with a sampling frequency of $31.25 \mathrm{~Hz}$ during a period of $180 \mathrm{~s}$. Seven cross sections were measured: three in the main channel $(X=$ $0.13 \mathrm{~m}, X=0.35 \mathrm{~m}$ and $X=0.53 \mathrm{~m}$ ), one in the axis of the tributary $(X=0.60 \mathrm{~m})$ and three in the postconfluence channel $(X=0.68 \mathrm{~m}, X=0.83 \mathrm{~m}$ and $X=1.33 \mathrm{~m})$. Their locations are presented in the Figure 3 . The transverse spacing of the measured profiles was $1.5 \mathrm{~cm}$ (Figure 4).

[20] Blanckaert and Lemmin [2006] have shown that a configuration with a central emitter symmetrically surrounded by four receivers at an angle of $45^{\circ}$ with respect to the principal flow direction gives redundant information in all three velocity components and is optimal with respect to noise reduction and temporal resolution. Due to constraints imposed by the size of the ADVP, this symmetrical configuration, however, only allowed measuring in the central region of the channel $(0.16 \mathrm{~m}<Y<0.35 \mathrm{~m})$. Near the outer $(0.06<Y<0.16 \mathrm{~m})$ and the inner $(0.35 \mathrm{~m}<Y<0.45 \mathrm{~m})$ banks, measurements were made with an asymmetrical configuration of the ADVP (Figure 4). The asymmetrical

Table 3. Characteristics of the Experiment $\mathrm{a}^{\mathrm{a}}$

\begin{tabular}{ccccccccccc}
\hline$Q_{m}\left(1 \mathrm{~s}^{-1}\right)$ & $Q_{t}\left(1 \mathrm{~s}^{-1}\right)$ & $Q_{t} / Q_{m}$ & $Q s_{t}\left(\mathrm{~kg} \mathrm{~min}^{-1}\right)$ & $F r_{m}$ & $F r_{t}$ & $F r_{p-c}$ & $M_{r}$ & Main & Tributary & Post-Confluence \\
\hline 18.0 & 2.0 & 0.11 & 0.3 & 0.32 & 1.30 & 0.70 & 0.2 & 5 & 7.5 & 7 \\
\hline
\end{tabular}

${ }^{a}$ Values are averaged in the main channel upstream of the confluence, the tributary, and the post-confluence channel. 
a) Asymmetrical ADVP(both sides)

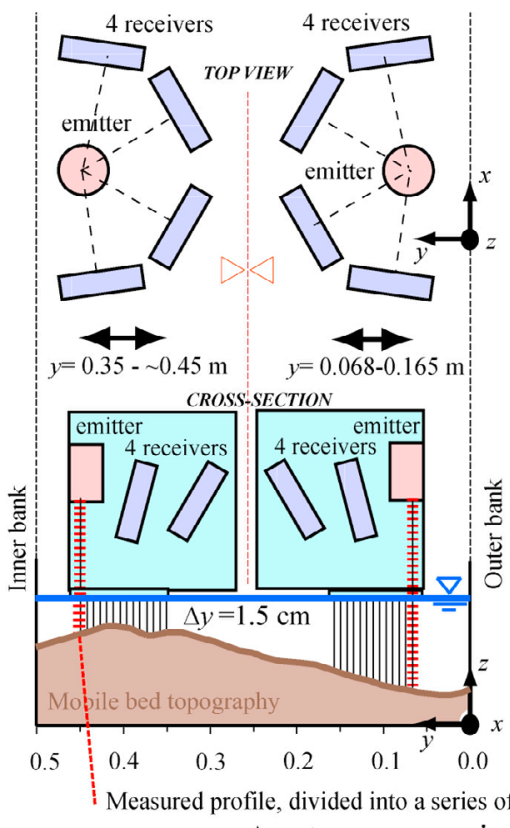

$\Delta y=$ transverse spacing between measured profiles

b) Symmetrical ADVP (center region)

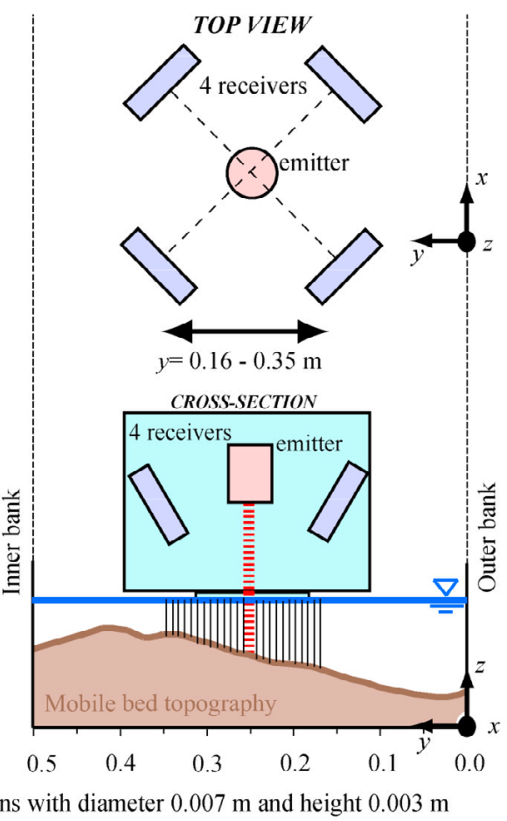

(a) asymmetrical and (b) symmetricalconfigurations Figure 4. Top views and cross sections showing the (a) asy
of the ADVP and the correspondent measurements grids.

configuration, however, only gives redundant information in the streamwise velocity component and is characterized by a higher noise level than the symmetrical one. This noise does not affect the time-averaged velocities, but it significantly biases the turbulent normal stresses and the estimation of the turbulent kinetic energy (tke), as described by Blanckaert and Lemmin [2006]. Therefore, results on the turbulence properties of the flow reported in the present paper will

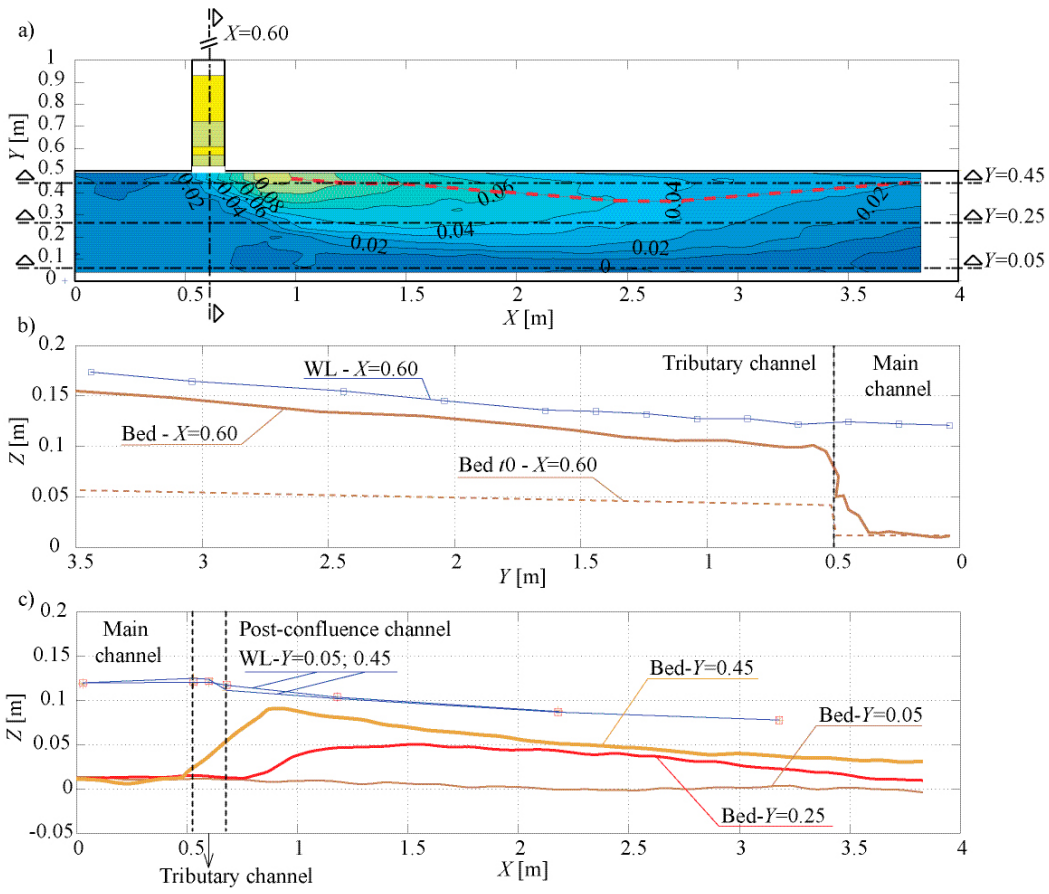

Figure 5. (a) Equilibrium bed topography at the main and postconfluence channels. (b) Longitudinal profiles of the water surface elevation and the equilibrium bed elevation at $X=0.60 \mathrm{~m}$ (axis of the tributary) and (c) $\mathrm{Y}=0.05 \mathrm{~m}$ (near the outer bank), $\mathrm{Y}=0.25 \mathrm{~m}$ (axis of the channel) and $\mathrm{Y}=0.45 \mathrm{~m}$ (near the inner bank). In Figure 5b, the initial bed elevation ( $(0)$ is indicated by the dashed line. 

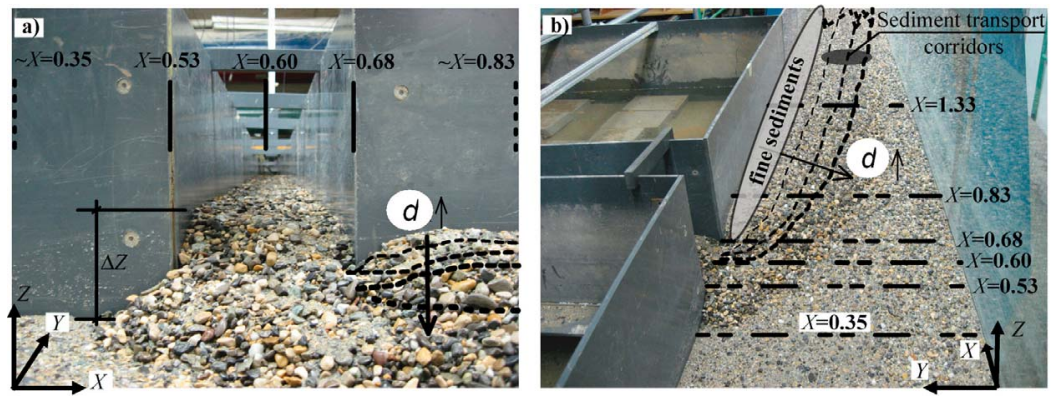

Figure 6. (a) View upstream into the tributary from the confluence zone and (b) view downstream into the postconfluence channel showing the preferential corridors of sediment transport (dashed lines over the sediment bar along the main channel). The thicknesses of the lines indicate qualitatively the increase of the transported particle diameters. The sediment diameter at the bed surface is indicated by $\mathrm{d}$ and the bed discordance by $\Delta \mathrm{Z}$.

uniquely be based on measurements with the symmetrical ADVP configuration in the central zone of the cross section.

[21] Blanckaert [2010] described in detail the working principle as well as the data treatment procedures for measurements with both ADVP configurations. He quantified the uncertainty in the measurement of the mean flow and turbulent flow quantities, which can be summarized as follows: about $4 \%$ in the time-averaged streamwise velocity $u_{x}$, about $10 \%$ in the cross-stream velocities $\left(u_{y}, u_{z}\right)$, about $20 \%$ in the turbulent normal stresses and the tke. The uncertainty in turbulence measurements increases progressively toward the bottom in the lower $20 \%$ of the water column. The uncertainty in depth-averaged mean velocities is estimated at less than $10 \%$.

\section{Bed Morphology, Water Surface Topography, and Sediment Transport}

[22] Figure 5a shows a view of the equilibrium bed morphology in the main and postconfluence channels as well as part of the tributary channel. The installed longitudinal slope of $0.5 \%$ and the water discharge of $2 \mathrm{l} \mathrm{s}^{-1}$ in the tributary were initially unable to transport the supplied sediment. As a result, the longitudinal slope in the tributary increased to an equilibrium value of about $1.9 \%$ that was able to transport the sediment discharge. At equilibrium, the flow in the tributary was uniform and supercritical $(F r \approx 1.30)$ with a flow depth of $0.02 \mathrm{~m}$ (Figure $5 \mathrm{~b}$ ) and velocities of about $0.6 \mathrm{~m} \mathrm{~s}^{-1}$. Flow in the main and postconfluence channels was subcritical, with $F r \approx 0.35$ and 0.70 , respectively. This change of flow regime in the confluence zone induced a weak undulated hydraulic jump [Chow, 1959] characterized by a small difference in water surface elevations.

[23] During the slope adjustment from the initial to the equilibrium bed slope, the tributary severely aggraded resulting in a pronounced discordance of about $0.09 \mathrm{~m}$ between the bed levels of the tributary and the main channel, which corresponds to $80 \%$ of the flow depth in the main channel upstream of the confluence and to more than four times the flow depth in the tributary. This bed discordance, which is clearly illustrated by the longitudinal profiles in the axis of the tributary (Figure 5b), is one of the most characteristic morphological features observed in the confluences of the Upper Rhone River.
[24] Longitudinal profiles in the main and postconfluence channels near the outer bank $(Y=0.05 \mathrm{~m})$, at the center $(Y=$ $0.25 \mathrm{~m})$ and near the inner bank $(Y=0.45 \mathrm{~m})$ illustrate the evolution of the morphology from the initial to the final state, as well as the equilibrium water surface elevation (Figure 5c). In the present experiment, weak scour only occurs near the outer bank in the postconfluence channel. The sediment discharge provided by the tributary builds a bar near the inner bank. Just downstream of the confluence $(X \approx 0.85 \mathrm{~m})$, this bar reaches a maximum height at the inner bank of about $0.09 \mathrm{~m}$, which is comparable to the discordance step height (Figure 5b). At the location of its maximum height, the bar (level $>0.02 \mathrm{~m}$ ) occupies about half of the width of the postconfluence channel. Further downstream, the maximum height of the bar decreases and the locus of maximum height is found at some distance from the inner bank, thereby creating a small depression adjacent to the inner bank that corresponds to a corridor of fine sediment transport, as indicated by the red dashed line at the crest of the bar (Figure 5a). Moreover, the bar widens downstream of the confluence reaching its maximum width at about $X=$ $2.6 \mathrm{~m}$. Downstream of this cross section, the morphology recovers toward a uniform, flat bed. Pronounced transverse slopes occur on the faces of the bar, especially in the confluence zone. In the axis of the tributary $(X=0.60 \mathrm{~m})$ the maximum slope of the face is around $47 \%\left(\sim 25^{\circ}\right)$ while at the cross section of maximum bar height the slope of the avalanche face is around $36 \%\left(20^{\circ}\right)$. These slope angles are slightly lower than the angle of repose of gravel $\left(\sim 40^{\circ}\right)$. The lateral slopes and the volume of the deposited material decrease considerably downstream.

[25] Figure 6 illustrates the preferential corridors of sediment transport based on visual observations. In the absence of a scour hole, sediment is transported along the face of the bar downstream of the confluence (Figure 6a). The corridor of sediment transport widens in the downstream direction and occupies the entire width of the postconfluence channel downstream of cross section $X=2.6 \mathrm{~m}$ (Figure 6). Visual observations clearly showed a sorting of the transported sediment in the confluence zone. The face of the bar is covered by the coarse fraction of the sediment mixture. But this coarse sediment is sorted and its diameter increases from the top toward the toe of the bar face. This grain sorting can be explained by the balance of the upslope drag force 


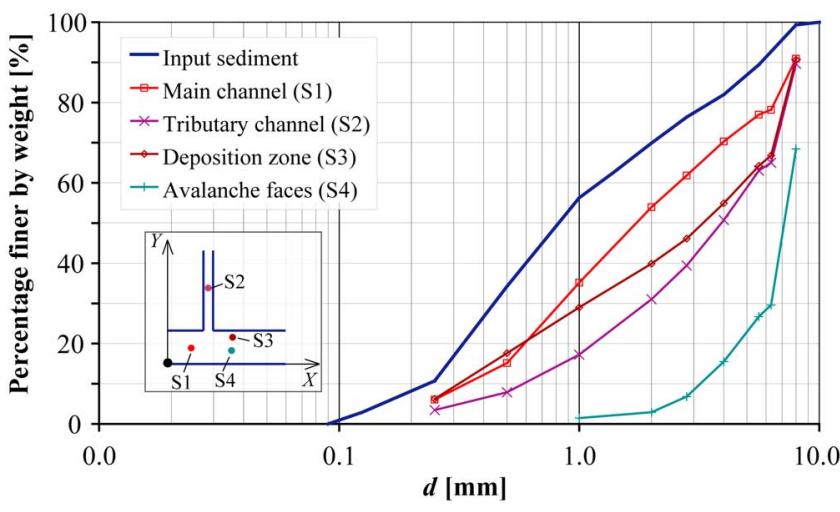

Figure 7. Grain size distribution of the input sediment and the different samples.

and of the downslope gravitational force on the grains: the former scales with the square of the sediment particle diameter whereas the latter scales with the cube of the sediment particle diameter [Sekine and Parker, 1992]. Both forces are in equilibrium for the average particle diameter found on the bar face, whereas the downslope/upslope forces are dominant for larger/smaller particles.

[26] The morphological depression at the inner bank in the postconfluence channel coincides with a narrow corridor of transport of fine sediment shown in Figure 6b. Visual observations showed that these fine sediments are lifted to the upper part of the water column by vertical spiral vortices that are locally generated at the downstream junction corner. No flow recirculation was observed in this zone during the experiment.

[27] Grain sorting in the confluence zone is further illustrated by means of grain size distributions (Figure 7) for surface samples in the main channel (S1), in the tributary (S2), on the top of the bar (S3) and on the face of the bar (S4). All of the sampled grain size distributions are coarser than the input sediment mixture, which is due to the transport in suspension of the fine sediment with a diameter of less than about $0.15 \mathrm{~mm}$. With the exception of some deposition in the inner-bank corridor (Figure 6b), these fine sediments are washed out of the flume. The bed in the main channel upstream of the confluence is armoured, with a $d_{50} \approx 1.8 \mathrm{~mm}$ at the surface, which is considerably larger than the median size of the input sediment mixture, $d_{50} \approx 0.8 \mathrm{~mm}$. The bed surface in the tributary (S2) is constituted by a coarse armor layer where $d_{50} \sim 4 \mathrm{~mm}$ and $d_{90} \sim 8 \mathrm{~mm}$. Sediment on top of the bar (S3: $d_{50} \sim 3 \mathrm{~mm}$ ) is finer than the tributary sediment, whereas the sediment on the face of the deposition bar is coarser than in the tributary (S4: $d_{50} \sim 7 \mathrm{~mm}$ ).

\section{Flow Dynamics}

\subsection{Depth-Averaged Flow Field}

[28] The entrance of the tributary causes considerable redistribution of the main channel flow. Figure 8 shows the patterns of the depth-averaged unit discharge $\left(U_{x} h, U_{y} h\right)$ and the depth-averaged velocities $\left(U_{x}, U_{y}\right)$, plotted over the bed topography in the confluence zone. Here $h$ represents the local flow depth. Upstream of the confluence, the flow distribution is symmetrical and typical for flow in narrow openchannels (see further details in section 4.2). The confluence globally causes a gradual outward redistribution of the discharge. In the cross section at $X=1.33 \mathrm{~m}$ the unit discharge at the outer bank is more than three times higher than at the inner bank.

[29] There is a clear relation between bed topography on the one hand and the magnitude and direction of the unit discharges on the other hand. The flow goes around the shallow bar at the inner bank and the major part of the discharge is concentrated over the deepest zone near the outer bank. These topographic effects, also called topographic steering, can largely be attributed to mass redistribution required by the principle of mass conservation [Blanckaert, 2010], which can be written as

$$
\frac{\partial \mathrm{U}_{\mathrm{x}} \mathrm{h}}{\partial \mathrm{X}}+\frac{\partial \mathrm{U}_{y} \mathrm{~h}}{\partial \mathrm{Y}}=0 \Rightarrow \mathrm{U}_{y} \mathrm{~h}=-\int_{0}^{\mathrm{Y}} \frac{\partial \mathrm{U}_{\mathrm{x}} \mathrm{h}}{\partial \mathrm{X}} d \mathrm{Y} .
$$

The major contribution in this mass conservation equation is due to the streamwise changes in bed topography and correspondingly in flow depth, $\partial \mathrm{h} / \partial X$.

[30] According to the majority of models, sediment transport is not primarily determined by the unit discharge, but rather by the local magnitude of bed shear stress $\left|\vec{\tau}_{b}\right|$, which is in first approximation (assuming a constant dimensionless Chézy friction coefficient $C_{f}$ ) proportional to the square of the magnitude of the local depth-average velocity $\left|\vec{\tau}_{b}\right|=\mathrm{C}_{\mathrm{f}} \sqrt{\mathrm{U}_{x}^{2}+\mathrm{U}_{y}^{2}}$. The momentum input by the tributary flow is clearly visible in the pronounced increase of

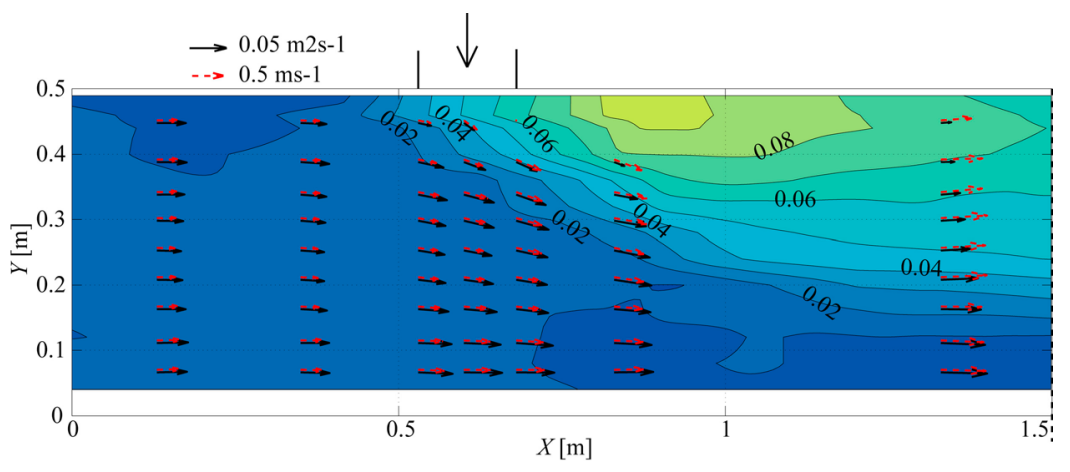

Figure 8. Contours of the bed topography and vector representations of the depth-averaged unit discharge $\left(U_{x} h, U_{y} h\right)$ (full vectors) and the depth-averaged velocities $\left(U_{x}, U_{y}\right)$ (dashed vectors). 


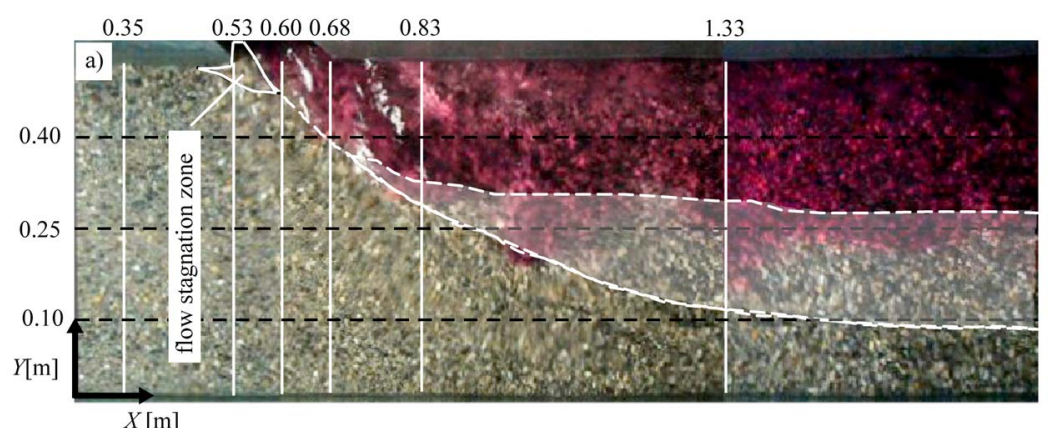

$X[\mathrm{~m}]$

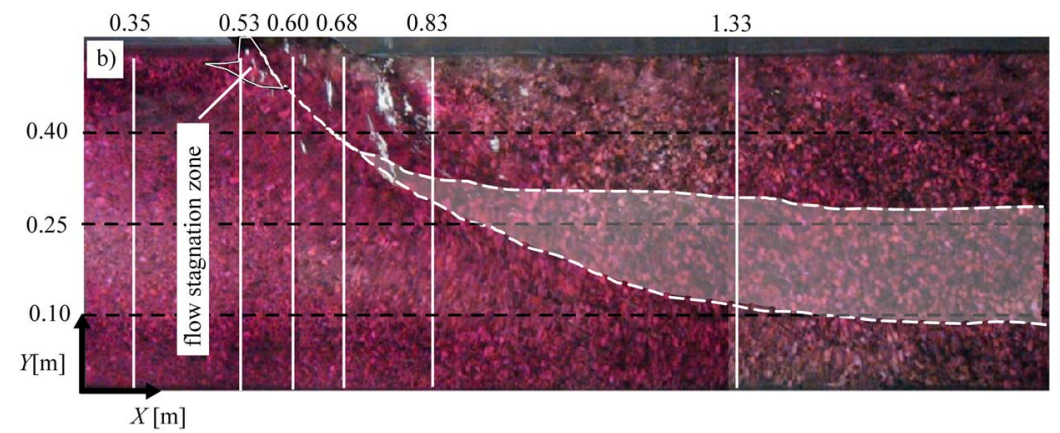

Figure 9. Flow visualization of the main and postconfluence channels with dye color injected (a) at the tributary and (b) at the main channel. The vertical lines correspond to the location of the cross sections where flow velocities have been measured. The location of the shear layer varies between the two dashed lines in the shadow zone.

the velocity magnitudes near the inner bank from the upstream $(X=0.53 \mathrm{~m})$ to the downstream $(X=0.68 \mathrm{~m})$ junction corners of the confluence (Figure 8). These increased velocities play an important role with respect to the transport of sediment originating from the tributary, as indicated by their coincidence with the observed corridors of sediment transport (Figure 6; see further in section 6).

\subsection{Three-Dimensional Flow Field}

[31] The transverse input of mass and momentum by the tributary, as quantified by the discharge ratio and the momentum flux ratio, creates a 3D flow field that includes, for example, skew-induced cross-sectional flow, turbulenceinduced helical flow and unsteady shear layers. The threedimensionality of the flow field is readily illustrated by flow visualization using color tracer introduced only in the tributary (Figure 9a) or only in the main channel (Figure 9b). This flow visualization clearly delineates the shear layer where flows from the main channel and the tributary join. There is a relation between the position of the shear layer on the one hand, and the sediment transport and bed morphology on the other. The preferential corridors of sediment transport coincide approximately with the shear layer (Figure 6 and Figure 9) and the outer limit of the shear layer coincides closely with the toe of the avalanche faces (Figure 8 and Figure 9).

[32] Flow from the tributary protrudes into the confluence zone and postconfluence channel and thereby changes its direction over a distance of about $1 \mathrm{~m}$ long. Ultimately, it occupies about half the width of the postconfluence channel. Flow from the tributary mainly remains near the water surface, which is due to the bed discordance of about $0.09 \mathrm{~m}$ (Figure 5b). At the upstream corner of the confluence $(X=$
$0.53 \mathrm{~m}$ ), the transverse inflow from the tributary is so strong that it blocks the flow coming from the main channel. This effect leads to the formation of a stagnation zone characterized by a rise of the water surface and deviation of the nearsurface flow toward the outer bank (Figure $5 \mathrm{c}$ ). Interestingly, part of the flow progresses into the postconfluence channel near the inner bank by plunging below the near-surface flow originating from the tributary (Figure 9b).

[33] This two-layer flow near the inner bank, which can be related to the marked bed discordance, leaves a strong footprint on the 3D flow field in the confluence zone. The relatively strong flow near the bed originating from the main channel prevents the formation of a flow recirculation zone over the shallow sediment deposition zone near the inner bank. Differences in magnitude and direction occur between the upper and lower layers of the flow. This is clearly seen in Figure 10, which shows a magnified region of the bed in the confluence zone as well as the near-bed and the near-surface average flow velocities at $Z / h=0.2$ (dashed vectors) and $Z / h=0.7$ (full vectors), respectively. In the confluence zone, the near-bed flow from the main channel follows a rather straight path that is directed upward the slope of the bar (most left near-bed vector in $X=0.60$ and $X=0.83$; Figure 11). The tributary inflow in this zone can be easily recognized by the near surface vectors that are outward directed (full ellipse in Figure 10). This tributary inflow deflects the near-surface flow originating from the main channel in the outward direction. Outside of the zone occupied by the bar (dashed ellipse in Figure 10), the near-bed flow is parallel to the bar contours while the near-surface flow is slightly less outward skewed. The skewing of the flow direction over depth does not lead to the formation of helical flow cells, however, because no upward/downward 


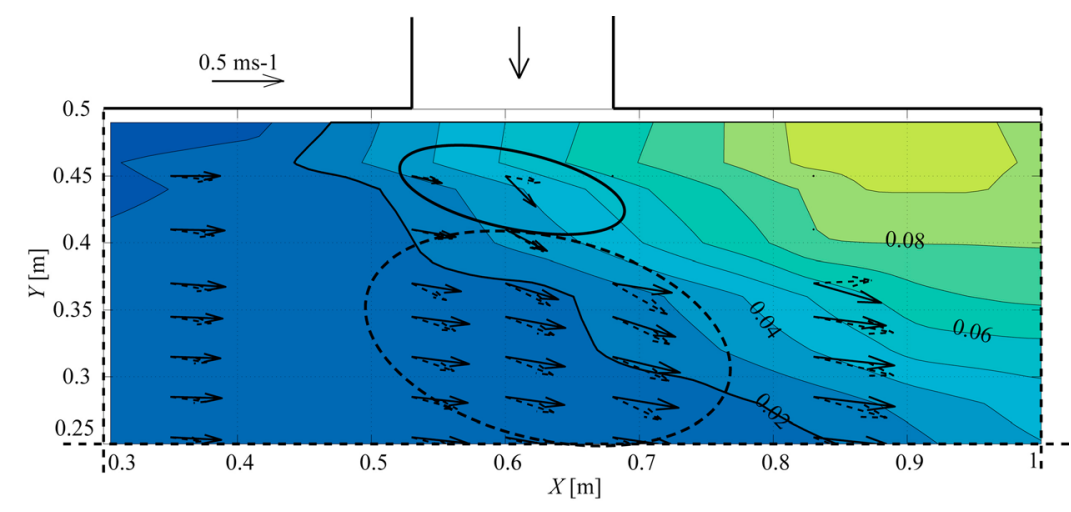

Figure 10. Zoom of the final bed topography in the confluence zone with the vectors $\left(\mathrm{u}_{\mathrm{x}}, \mathrm{u}_{\mathrm{y}}\right)$ near the bed at $Z / h=0.2$ (dashed vectors) and near the surface at $Z / h=0.70$ (full vectors).

vertical velocities occur that are of similar magnitude to the variation of the transverse velocity component (Figure 11).

[34] Figure 11 shows the vectors of the cross-sectional velocities $\left(u_{y}, u_{z}\right)$ superimposed on the contours of the streamwise velocity $u_{x}$. The flow upstream of the confluence $(X=0.13 \mathrm{~m}$ and $X=0.35 \mathrm{~m})$ shows a pattern that is typical for open-channel flow in a relatively narrow rectangular cross section $(B / H=5)$ with a rough bed [Tominaga et al., 1989; Nezu and Nakagawa, 1993; Rodríguez and Garcia, 2008; Blanckaert et al., 2010]. The flow distribution is about symmetrical over the width of the channel, but shows significant transverse variations with amplitude of about $10 \%-15 \%$ in the streamwise velocities. Moreover, the maximum streamwise velocities are found below the water surface, a phenomenon commonly called the velocity dip. This velocity distribution is the result of advective transport of momentum by helical flow cells. These cells are induced by turbulence, reach maximum cross-stream velocities of about $0.02 \mathrm{U}$, and scale with the flow depth, which explains the existence of four cells over the width of the channel [Blanckaert et al., 2010]. These four cells are schematically indicated in Figure 11a. Regions of downward vertical velocities ( $Y=0.1 \mathrm{~m}$ and $Y=0.4 \mathrm{~m}$; Figure 11a) advect highnear-surface velocities toward the bed and cause an increase in streamwise velocity in the water column, whereas regions of upward vertical velocities ( $Y=0.25 \mathrm{~m}$; Figure 11a) advect low-near-bed velocities toward the water surface and cause a decrease in streamwise velocity in the water column.

[35] The cross section at $X=0.35 \mathrm{~m}$ (Figure 11b) is characterized by a slight rise of the water surface near the inner bank, an outward mass flux in the inner part of the cross section, and a weak outward shift of the streamwise velocity pattern. This slight asymmetry can be attributed to the effect of the entrance of the tributary flow, which perturbs the flow upstream of the confluence where flow is subcritical.

[36] According to the flow visualization in Figure 9a, flow in the cross section located at the upstream corner of the confluence $(X=0.53 \mathrm{~m}$, Figure 11c) uniquely originates from the main channel and is not yet affected by momentum input from the tributary. However, flow upstream of the junction corner is already strongly conditioned by the confluence and shows considerable outward velocities that are accompanied by a global decrease of velocities in the inner part of the cross section and a global increase of velocities in the outer part. Different processes contribute to this velocity redistribution. Topographic steering due to the presence of the bar just downstream that directs the flow outward is a dominant process contributing to the velocity redistribution. As shown by the flow visualization, the flow coming perpendicularly from the tributary acts as an obstacle that causes a stagnation zone characterized by a rise in the water level near the inner bank, flow deceleration, and flow deflection in the outward direction (Figure 5c). The effect of the obstruction by the tributary inflow is especially strong near the water surface, as visible in the bulging of the $u_{x}$ contours. These processes originate where the tributary flow enters and diminish with distance from the inner bank. The vertical $u_{x}$-contours near the water surface at the inner bank and the strong lateral velocity gradient suggest the development of a shear layer.

[37] The pronounced transverse velocities near the inner bank in the cross sections situated in the confluence zone $(X=0.60 \mathrm{~m}$ at the axis of the tributary and $X=0.68 \mathrm{~m}$ at the downstream corner of the confluence) represent the transverse inflow from the tributary. The pattern of vectors follows the bed topography and the magnitude of crossstreamflow diminishes with distance from the inner bank, which reflects change in the direction of flow (see visualization in Figure 9a). These transverse velocities are higher at $X=0.68 \mathrm{~m}$ than at $X=0.60 \mathrm{~m}$, indicating that the flow in the tributary is asymmetrical with higher velocities toward the downstream junction corner. The momentum input by the tributary increases the magnitudes of velocity vectors near the inner bank (Figure 10) and the core of highestvelocity magnitudes is located near the inner bank close to the bed. This core of highest velocities is of particular importance for the transport of sediment originating from the tributary (see further in section 6). The outward velocities lead to an outward shift of the location of the shear layer (at about $Y=0.37 \mathrm{~m} / 0.32 \mathrm{~m}$ in the cross sections at $X=$ $0.60 \mathrm{~m} / 0.68 \mathrm{~m})$. Velocities near the inner bank are smallest at the water surface and increase considerably toward the bed, confirming the two-layer structure of the flow at this location.

[38] The confluence-induced flow processes persist in the cross section downstream of the confluence at $X=0.83 \mathrm{~m}$. The transverse velocities near the inner bank have weakened, 

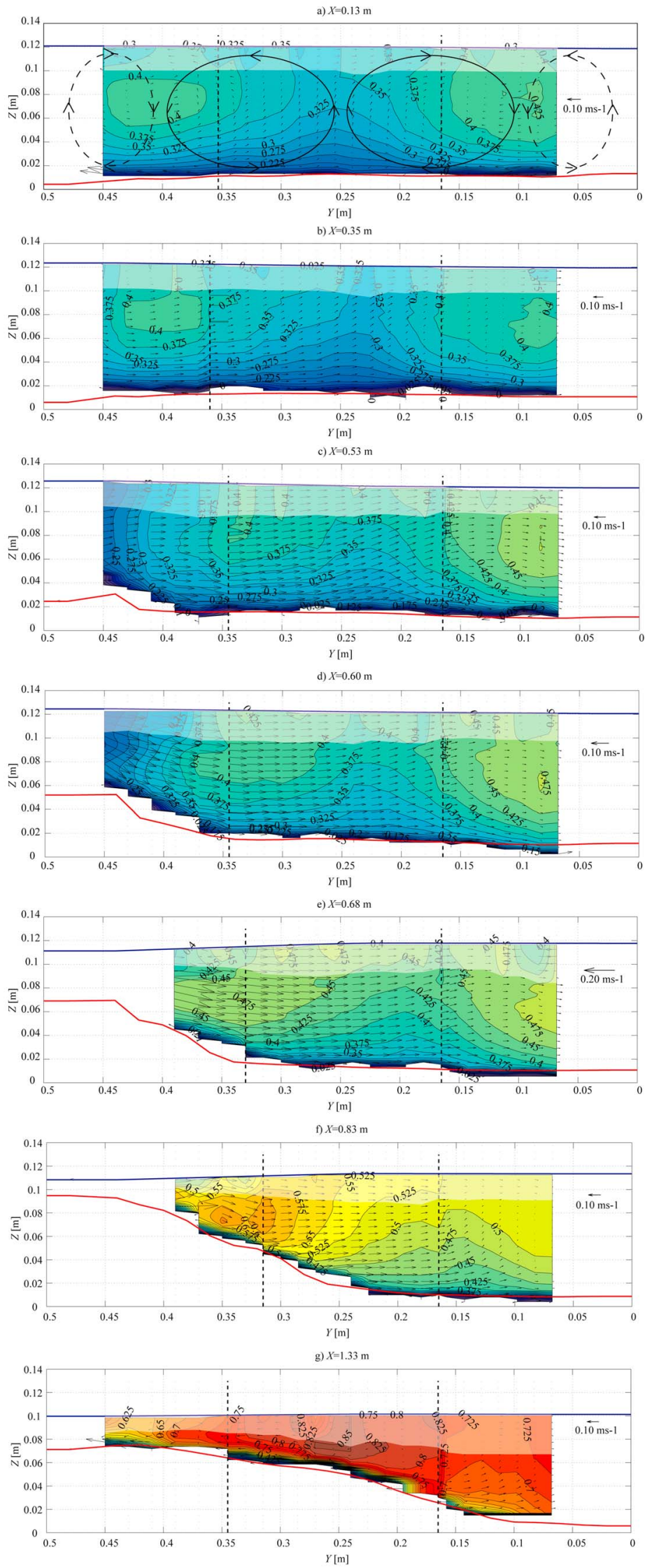

Figure 11 
but the two-layer flow structure and the core of highest velocities close to the bed near the inner bank are still pronounced. This cross section is characterized by considerable acceleration of the flow, especially on the slope of the bar face near the inner bank. This flow acceleration, which plays an important role in the transport of sediment (see further in section 6), can be attributed to three effects. First, the sediment deposition zone near the inner bank reaches its maximum height, which leads to a considerable reduction of the flow cross section in the postconfluent channel. Second, the near-surface flow originating from the tributary occupies about half of the width (see dye visualization in Figure 9a), which leads to a contraction and a further reduction of the flow area. Third, this reduction of the flow area is accompanied by a backwater effect that provides the local steepening of the water surface (Figure 5c) required to accelerate the flow. The shear layer, located around $Y=0.25 \mathrm{~m}$ according to the dye visualization in Figure 9, has considerably weakened as indicated by the attenuated transverse gradient in the nearsurface velocities.

[39] Velocities are rather low in the shallowest part $(Y>$ $0.4 \mathrm{~m}$ ) of the cross section over the top of the bar at $X=1.33 \mathrm{~m}$. Outward mass and momentum transport between the cross sections at $X=0.83 \mathrm{~m}$ and $X=1.33 \mathrm{~m}$ has shifted the core of maximum velocities to the central zone of the channel. Interestingly, it occurs over the bar face and not over the deepest part of the cross section. Inward movement of fluid is observed in the inner part of the cross section, which is due to expansion of flow over the bar and the decreasing transverse bed slope (Figure 5a). This cross section is marked by considerable global flow acceleration accompanied by an increase of the postconfluence water surface slope (Figure 5b).

[40] It is interesting to note that the signature of the turbulence-induced helical flow cells observed in the cross sections at $X=0.13 \mathrm{~m}$ and $X=0.35 \mathrm{~m}$ remain visible onto the last measured cross section at $X=1.33 \mathrm{~m}$, in the form of the bulging of the $u_{x}$-isolines and the two cores with increased streamwise velocities. These features are shifted outward, however, by the flow originating from the tributary, and they only occur in the confluence zone at the outside of the shear layer. Moreover, the transverse velocities of these turbulence induced helical flow cells of about $0.02 U \approx 0.01 \mathrm{~ms}^{-1}$ are more than an order of magnitude smaller than the transverse velocities generated by the lateral inflow from the tributary. These observations indicate that these helical cells do not modify considerably the $3 \mathrm{D}$ flow processes induced by the channel confluence.

\subsection{Turbulent Flow Structure}

[41] The confluence enhances turbulence activity, which is relevant with respect to the mixing of mass, momentum, heat, suspended matter and sediment coming from the main channel and the tributary. Figure 12 shows the normalized turbulent kinetic energy, tke $/ u_{*}^{2}$, in the cross sections at $X=$ $0.13 \mathrm{~m}, X=0.68 \mathrm{~m}$ and $X=0.83 \mathrm{~m}$. These cross sections were chosen because of their representativeness in terms of turbulent structure in a confluence zone. The characteristic shear velocity $u_{*}$ used for the normalization is calculated between $X=0.13 \mathrm{~m}$ to $X=1.33 \mathrm{~m}$ and is equal to $0.04 \mathrm{~m} \mathrm{~s}^{-1}$. As mentioned in section 2, only turbulence measurements with the symmetrical ADVP configuration are discussed.

[42] The pattern of tke in the cross section at $X=0.13 \mathrm{~m}$ is typical of straight channel flows in narrow rectangular cross sections. The turbulence is mainly induced by bottom friction and redistributed in the cross section by the turbulenceinduced helical flow cells (Figure 12a) that cause transverse variations in the tke [Blanckaert et al., 2010]. These patterns subsist in the central parts of the cross sections at $X=0.68 \mathrm{~m}$ and $X=0.83 \mathrm{~m}$, but they are slightly advected outward by the transverse velocities associated with the tributary inflow (Figure 12). The most noticeable features in the cross sections at $X=0.68 \mathrm{~m}$ and $X=0.83 \mathrm{~m}$ are the increased and pronounced gradients in tke near the inner edge of the measuring grid. These gradients correspond to the position of the shear layer as identified by means of dye flow visualization (Figure 9) and the mean velocity patterns (Figure 11). Also the momentum input by the tributary flow contributes considerably to the tke increase: it increases the magnitude of the velocities in the confluence zone (Figure 11) and hence also the turbulence activity, since tke scales with the square of the mean velocity magnitude. In the cross section at $X=0.68 \mathrm{~m}$, the pronounced tke gradient is only apparent near the water surface, which is in agreement with the pronounced vertical two-layer flow structure in this zone (Figure 11). Interestingly, the core of pronounced tke increase in the shear layer approximately coincides with the preferential corridors of sediment transport (Figure 6b).

[43] Figure 13 presents the relative contributions to the tke of the streamwise, transverse and vertical velocity fluctuations at a relative depth of $Z / h=0.7$ in the cross sections at $X=0.13 \mathrm{~m}, X=0.68 \mathrm{~m}$ and $X=0.83 \mathrm{~m}$. Upstream of the confluence in the cross section at $X=0.13 \mathrm{~m}$, the contribution of $\overline{u_{x}^{\prime 2}}, \overline{u_{y}^{\prime 2}}$ and $\overline{u_{z}^{\prime 2}}$ are about $58 \%, 30 \%$, and $12 \%$, respectively, which is in agreement with the semitheoretical values for straight open-channel flows presented by Nezu and Nakagawa [1993] and the experimental values measured in straight natural rivers by Sukhodolov et al. [1998]. In the cross section at $X=0.68 \mathrm{~m}$, the tributary input of transverse momentum causes an increased relative contribution of $\overline{u_{y}^{\prime 2}}$, which weakens with transverse distance from the confluence zone. Interestingly, although the mean flow reorients in the streamwise direction between the cross sections at $X=0.68 \mathrm{~m}$ and $X=0.83 \mathrm{~m}$ (Figure 11 and Figure 12), $\overline{u_{y}^{\prime 2}}$ continues to grow at the expense of $\overline{u_{x}^{\prime 2}}$ in the inner part of the cross section where the transverse fluctuations form the dominant contribution to tke. The cross-stream patterns also indicate that the relative magnitude of the transverse velocity fluctuations increase within the shear layer. This finding is consistent with

\footnotetext{
Figure 11. Mean streamwise flow velocities $u_{\mathrm{x}}$ (contours) and cross-sectional velocities, $\mathrm{u}_{\mathrm{y}}$, $\mathrm{u}_{\mathrm{z}}$ (vectors) at the seven measured cross sections indicated in Figure 3. The two vertical dashed lines represent the boundaries between measurements performed with the asymmetrical and symmetrical ADVP configurations, whereas the shaded areas indicate regions where the flow measurements are perturbed by the ADVP housing that touches the water surface (more details in the work of Blanckaert [2010]).
} 

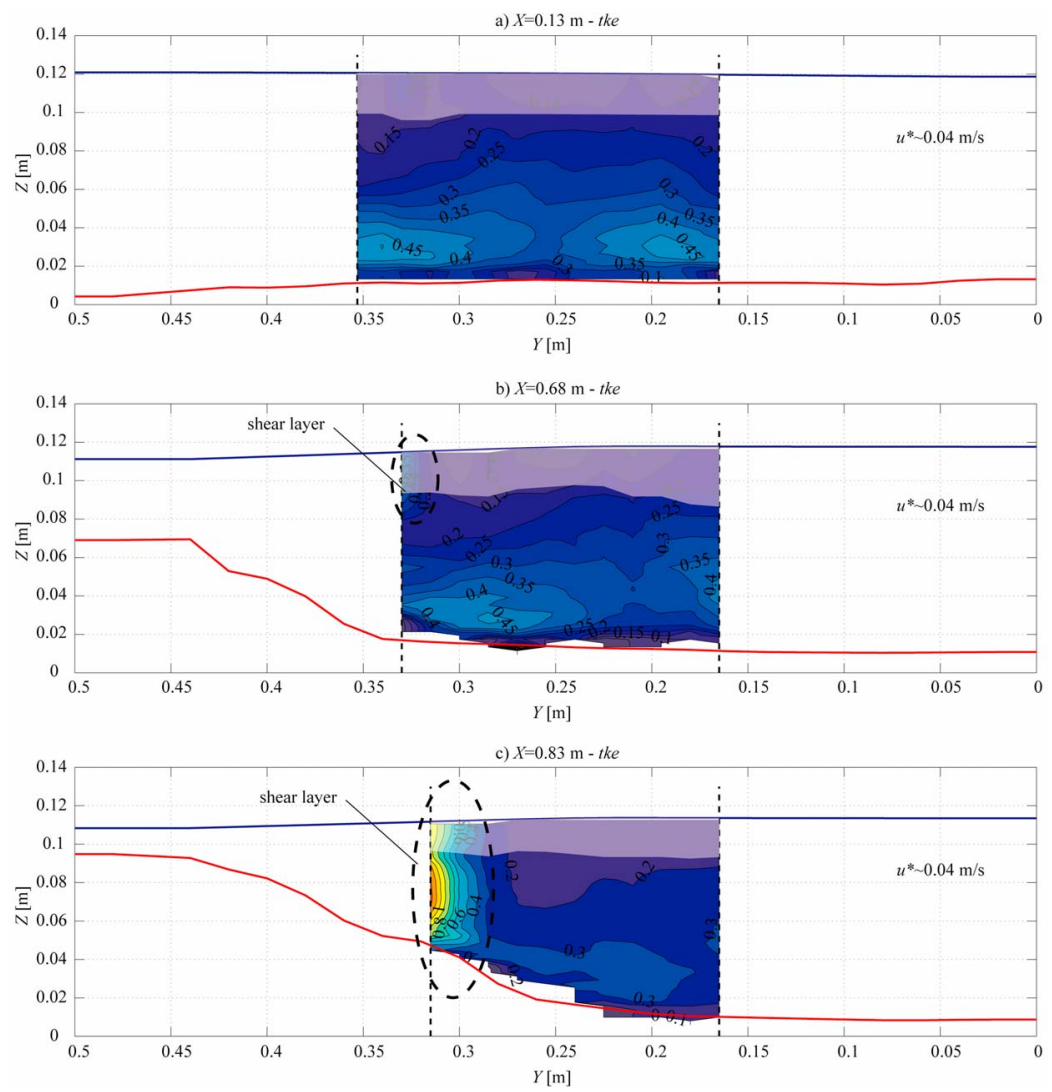

Figure 12. Patterns of normalized turbulent kinetic energy $t k e / u_{*}^{2}$ in the cross sections at (a) $X=0.13 \mathrm{~m}$, (b) $\mathrm{X}=0.68 \mathrm{~m}$, and (c) $\mathrm{X}=0.83 \mathrm{~m}$. The shaded areas indicate regions where the flow measurements are perturbed by the ADVP housing that touches the water surface (more details in the work of Blanckaert [2010]).

the results of Sukhodolov and Rhoads [2001] in small natural confluences with concordant beds.

\section{Representativeness of the Experimental Results}

[44] The present section discusses the relevance of the results obtained in the schematized laboratory setup under constant conditions of discharge and sediment supply by means of comparison to field observations on the confluence of the Upper Rhone River and the Lonza tributary shown in Figure 14. In spite of differences in the main geometrical and hydraulic parameters, the experiment reproduced satisfactorily the main features observed in the Rhone-Lonza confluence, which lends credence to the results of the laboratory investigation. The Lonza-Rhone confluence is marked by a significant discordance. The confluence promotes the formation of a deposition bar that occupies around $75 \%$ of the channel width in the cross section at km 99.384 (Figure 14a). The bar deflects the main flow toward the left bank, generating flow acceleration and consequently creating a small erosion zone near the left bank (Figure 14b). This zone of erosion is situated near the region where the highest unit discharge was observed in the laboratory experiment (Figure 10). As for the reported experiment, the erosion is considerably smaller than the deposition. The bar is characterized by significant grain sorting, where fine and coarse materials regions can be recognized in Figure 14c. During low flows, the bar is exposed and the flow is redistributed to the left bank. A well-marked shear layer is formed between the confluent flows (Figure 14c).

[45] Investigations on the Bayonne-Berthier confluence [Leclair and Roy, 1997; Boyer et al., 2006], and on the confluence of the Kaskaskia River and Copper Slough [Rhoads et al., 2009] have reported that the bed morphology and the bed material texture cyclically respond to the
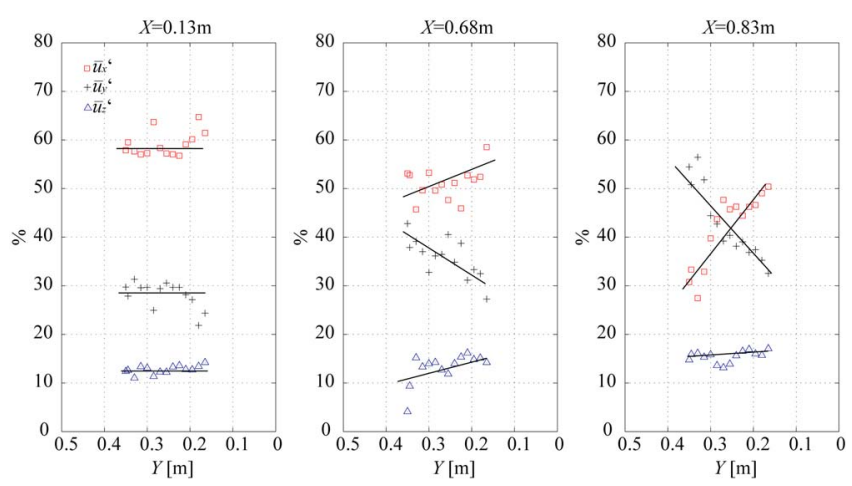

Figure 13. Relative contributions of $\overline{u_{x}^{\prime 2}}, \overline{u_{y}^{\prime 2}}$ and $\overline{u_{z}^{\prime 2}}$ on the turbulent kinetic energy in the cross sections $X=0.13 \mathrm{~m}$, $\mathrm{X}=0.68 \mathrm{~m}$, and $\mathrm{X}=0.83 \mathrm{~m}$ near the water surface $(\mathrm{Z} / \mathrm{h}=$ $0.70)$. 

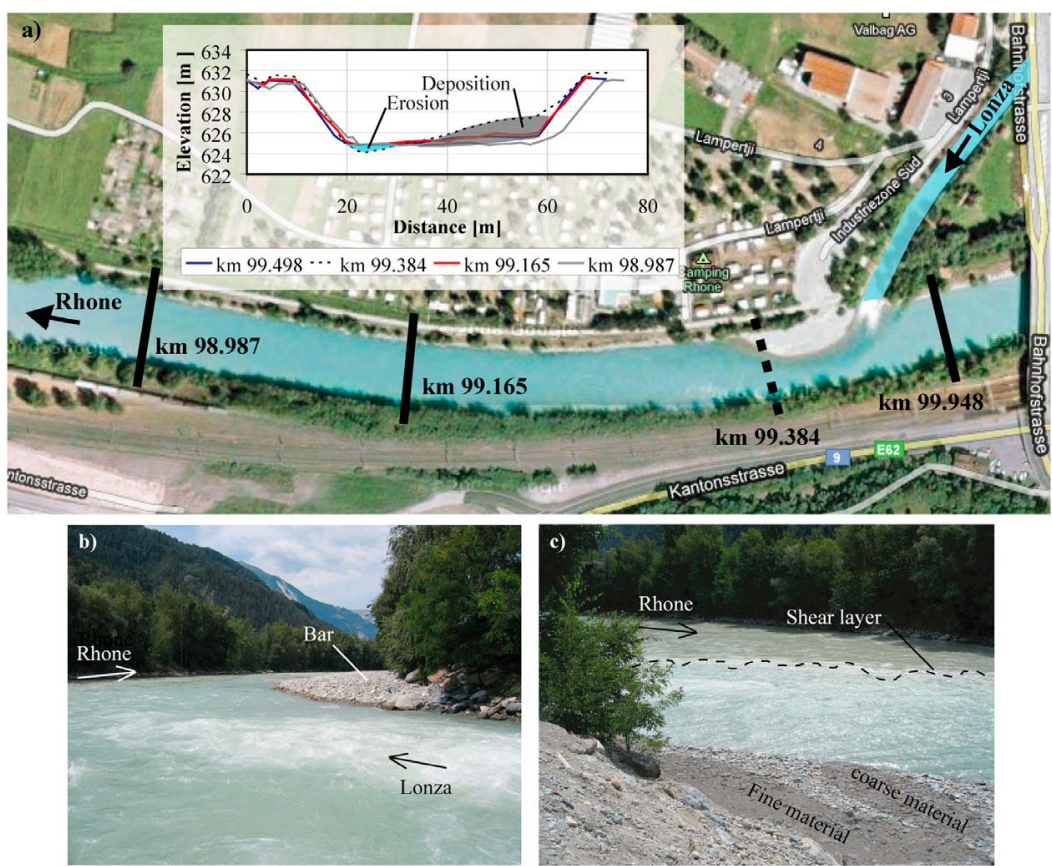

Figure 14. Confluence of the Upper Rhone River and the Lonza in Switzerland $\left(48^{\circ} 18^{\prime} 23^{\prime \prime} \mathrm{N} / 7^{\circ} 44^{\prime} 35^{\prime \prime} \mathrm{E}\right)$ during low-flow conditions. (a) Aerial view (Google Earth imagery $\mathbb{C}$ Google Inc.) showing 4 cross sections. (b) Picture taken from the tributary toward downstream and (c) picture taken from the right bank at the deposition zone from upstream. The confluence is characterized by a junction angle of $65^{\circ}$ and the parameters $\mathrm{B}_{\mathrm{t}} / \mathrm{B}_{\mathrm{m}}=0.11, \mathrm{Q}_{\mathrm{t}} / \mathrm{Q}_{\mathrm{m}}=0.1, \mathrm{Fr}_{\mathrm{t}} \sim 1.0$ and $\mathrm{M}_{\mathrm{r}}=0.1$. The aerial view, the cross sections, and the pictures taken at the confluence do not represent the same time and discharges.

hydrological variability in the momentum flux ratio and the associated sediment supply. In natural cases with intermittent sediment supply from the confluent channels only during floods, the bar can be expected to grow during flood events when the sediment supply exceeds the sediment transport capacity. After a flood when the sediment supply has decreased, however, the bar can be expected to erode until equilibrium is established.

\section{Hydro-morpho-sedimentary Processes}

[46] The previous sections reported and analyzed separately the bed morphology and the sediment transport on the one hand, and the flow dynamics on the other hand. Figure 15 attempts to integrate the foregoing observations in a conceptual model for the hydro-morpho-sedimentary in confluences with similar characteristics. In this section, we will discuss the model's main features, and contextualize the results with respect to foregoing investigations on confluence morphodynamics. This contextualization will focus on the similarities with and differences from conceptual models proposed by Best [1988], Boyer et al. [2006], Leclair and Roy [1997] and Rhoads et al. [2009] for channel confluences with different characteristics (cf. Table 1).

\subsection{Bed Discordance in the Confluence Zone}

[47] The most peculiar characteristic of the investigated type of confluence is the pronounced bed discordance in the confluence zone (Figure 5; cf. Table 1). Flow in the postconfluence channel is subcritical and hence by definition conditioned by the downstream boundary conditions for the water surface elevation and the bed level. The total discharge, $Q_{m}+Q_{t}$, and sediment supply, $Q_{s, m}+Q_{s, t}$, originating from the main channel and the tributary determine the (cross-sectional-averaged) flow depth and the bed slope in
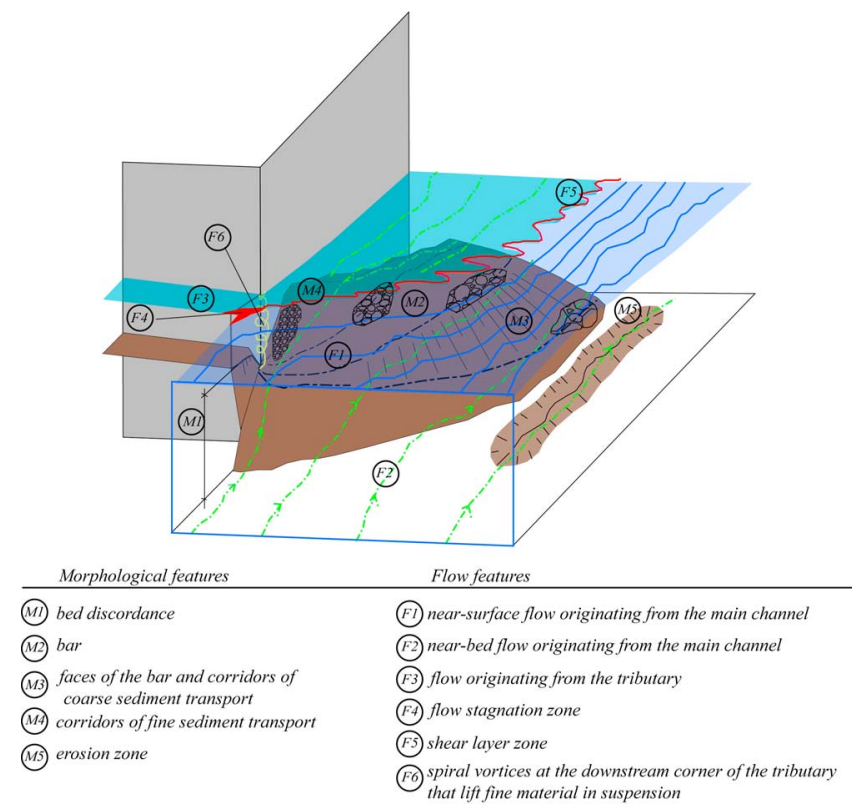

Figure 15. Conceptual framework of hydro-morphosedimentary processes in channel confluences with lowdischarge and momentum flux ratios and high bed load transport ratio such as found in the Upper Rhone basin. 


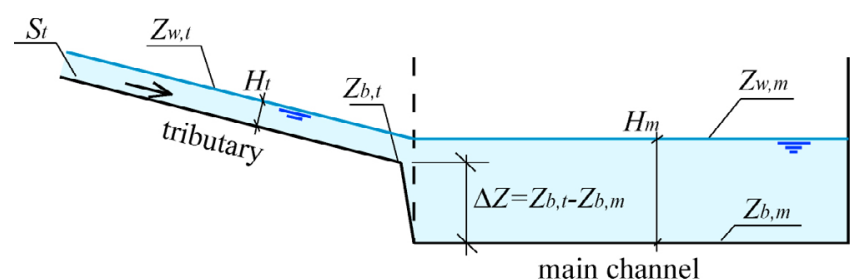

Figure 16. Conceptual model for bed discordance.

the postconfluence channel, and hence also the absolute elevations of the bed and the water surface in the confluence zone, $Z_{b, m}$ and $Z_{w, m}$, respectively (Figure 16). These considerations do not take into account the three-dimensionality of the bed topography in the postconfluence channel. In the reported experiment, this three-dimensionality mainly occurs downstream of the confluence due to the sediment supply by the tributary, and it is much less pronounced in the confluence zone where the bed discordance is observed (Figure 5a).

[48] In the confluence zone, it can reasonably be assumed that the water levels in the main, the tributary and the postconfluence channels are about equal under formative hydrological conditions. Contrary to the case of junctions where the flow is subcritical in both confluent channels, a hydraulic jump has to occur in the investigated type of confluence to accommodate the transition from the supercritical flow in the tributary to the subcritical flow in the postconfluence channel. The characteristics of a hydraulic jump are mainly determined by $F r_{m}$ and $F r_{t}$. For the range of Froude numbers encountered in the experiment $\left(F r_{m}=0.32\right.$ and $\left.F r_{t}=1.3\right)$, a weak undulated hydraulic jump occurs that only induces a small difference in water level elevations in the confluence zone, $Z_{w, m} \approx Z_{w, t}$.

[49] The discharge $Q_{t}$, the sediment supply $Q_{s, t}$ and the sediment characteristics in the tributary determine the flow depth, $H_{t}$, and the bed slope $S_{t}$. The absolute elevations of the bed and water surface are determined by the downstream boundary conditions in the confluence zone. The absolute elevation of the bed level is determined by $Z_{b, t}=Z_{s, t}-H_{t}$. The bed discordance is readily obtained as $Z_{b, t}-Z_{b, m} \approx H_{m}-H_{t}$.

[50] This explanation and quantification corroborates the claim of Kennedy [1984] that the bed discordance is controlled by the physiographic characteristics of the two watersheds of the main river and the tributary, which determine the size, shape and hydraulic conditions of the confluent channels, rather that by the confluence dynamics itself. The pronounced bed discordance in the investigated type of confluence can primarily be attributed to the different flow and sediment transport regimes in the tributary and main channels.

[51] The moderate discordance observed in the BayonneBerthier confluence [Biron et al., 1993b; Boyer et al., 2006] and the mild discordance between the Kaskaskia and the Copper Slough Rivers [Rhoads and Kenworthy, 1995; Rhoads and Kenworthy, 1998; Rhoads et al., 2009] and the laboratory confluence channels studied by Best [1988] can be explained by the similarity of the flow depths $\left(H_{t}\right.$ and $\left.H_{m}\right)$ and sediment transport regimes between the tributaries.

\subsection{Flow Features in the Confluence Zone}

[52] The pronounced bed discordance strongly conditions the flow processes in the confluence zone and is at the origin of the formation of a two-layer flow structure. Flow originating from the tributary mainly protrudes in the upper part of the water column of the main channel, where it deflects the main-channel flow outward.

[53] The bed discordance shields the flow in the lower part of the water column from the tributary inflow, and allows it to move unimpeded downstream (Figure 9, Figure 10, Figure 11), which prevents the formation of a zone of horizontal flow recirculation. In configurations with mild bed discordance such as Best's [1988] laboratory experiments or the confluence of the Kaskaskia River and Copper Slough, the tributary flow deflects the main-channel flow outward over the entire flow depth. The directional change of the tributary can induce a zone of horizontal flow recirculation at the inner bank [Best and Reid, 1984] where mainly fine sediment tends to settle and build a separation zone bar. The absence of horizontal flow recirculation in the BayonneBerthier confluence, in the experiments performed by Biron et al. [1993a] in a confluence flume with fixed bed with a mild bed discordance without sediment transport, and in the laboratory experiment reported here confirm the role of the two-layer flow structure in preventing flow recirculation.

[54] Helical flow cells were observed in Mosley's [1976] and Best's [1987] laboratory experiments and in the confluence of the Kaskaskia River and Copper Slough [Rhoads and Kenworthy, 1995; Rhoads and Kenworthy, 1998; Rhoads et al., 2009]. However, such cells were not observed in the Bayonne-Berthier confluence [Biron et al., 1993b; Biron et al., 2002; Boyer et al., 2006] nor in the experiments of Biron et al. [1996b] and that reported here, both of which had pronounced bed discordances. Similar to open-channel bends, helical flow is generated in confluences with concordant or mildly discordant beds by curvature effects, and more specifically by vertical gradients in the centrifugal force that are mainly due to bottom friction [Blanckaert and de Vriend, 2004]. An increase in bed discordance can be expected to reduce the effect of bottom friction and hence the tendency to helical flow generation. Moderate and pronounced bed discordances limit the tributary flow penetration to the upper part of the flow depth and disconnect this flow from bed frictional influences, which explains the absence of helical flow.

[55] A shear layer characterized by increased turbulence levels at the junction of the flows originating from the tributary and the main channel is a common feature in channel confluences with both bed concordant or bed discordant configurations [Best and Roy, 1991; Biron et al., 1996b; Bradbrook et al., 2000b; Sukhodolov and Rhoads, 2001; Biron et al., 2004; Rhoads and Sukhodolov, 2008]. The shear layer is tridimensional as it develops both laterally and vertically in the confluence zone. The shear layer position is critical for the dynamics of the confluence as it influences flow mixing and sediment transport pathways. This position will vary according to the discharge ratio and the height of the bed discordance thus affecting the resulting bed morphology.

\subsection{Morphological Features in the Confluence Zone}

[56] Sediment continuity requirements explain the morphology in the reported experiment, which included the development of a bar at the inner bank and weak scour at the outer bank (Figure 5). The steep slope provided by the bed discordance promotes delivery of coarse sediment from the 
tributary into the confluence zone, where it encounters the near-bed flow originating from the main channel. Initially, this near-bed flow has insufficient sediment transport capacity, leading to the deposition of the sediment and the development of the bar. This bar development causes, however, a reduction in the local flow depth accompanied by a backwater effect that locally steepens the longitudinal water surface gradient (Figure 5c), which leads to an acceleration of the flow. This flow acceleration, together with enhanced near-bed velocities (Figure 11) and enhanced turbulence (Figure 12), provide the sediment transport capacity required to carry the sediment load from the tributary through the confluence.

[57] A similar morphology characterized by a bar along the inner bank of the downstream channel and limited scour at the opposite bank was observed in the Bayonne-Berthier confluence [Biron et al., 1993b; Leclair and Roy, 1997; De Serres et al., 1999; Boyer et al., 2006], which is characterized by a moderate bed discordance and dominant sediment supply by the tributary. Also at the confluence of Kaskaskia River and Copper Slough [Rhoads and Kenworthy, 1995; Rhoads and Kenworthy, 1998; Rhoads et al., 2009], the development of large bars at the downstream junction corner occurred when the lateral tributary was dominant and large amounts of bed load were transported into the confluence from this tributary. In most scenarios investigated by Rhoads et al. [2009] on the confluence of Kaskaskia River and Copper Slough, the bed discordance remained mild. Rhoads et al. [2009] also noted that scour was limited over the outer half of the cross section under such cases and that it was as much related to lack of deposition (extension of the bar laterally) as it was to active scour. In the conceptual model proposed by Best [1988], the dominant morphological feature is a scour hole that connects to the tributary and the upstream main channel by means of steep avalanche faces that promote the delivery of sediment to the confluence zone.

[58] The interplay between sediment loads and the discharges in the tributary and the main channel appears to be an important factor governing confluence morphology, including the development, relative importance and location of scour, deposition and bed discordance. Our observations, associated with the analyses of previous studies suggest that the degree of discordance is greatest and the degree of scour is most limited when the tributary is dominant in terms of bed load rates and bars form in the confluence zone. Scour is most pronounced when both the tributary and main channel transport abundant sediment and the continuity of both loads through the confluence must be maintained.

[59] In the reported experiment, the increase in velocity in the confluence zone due to the deposition bar is accompanied by an increase in the energy gradient (which scales with the square of the velocity), as illustrated by the marked increase in the water surface slope downstream of the confluence (Figure 5c). This finding is in agreement with experimental evidence of flow acceleration downstream of confluences in natural rivers [Roy and Roy, 1988; Roy et al., 1988; Rhoads and Kenworthy, 1995; Rhoads et al., 2009]. Rice [1999] and Rice and Church [2001] observed related steepening of the bed (and bed material coarsening) of the main channel downstream of tributaries that introduce excess coarse bed material.
[60] Topographic steering around the bar shifts the flow toward the outer bank. In the reported experiment, the unit discharge was found to be three times higher at the outer bank than at the inner bank (Figure 8). This convective acceleration of the flow explains the zone of erosion found along the outer bank. These observations are in line with the erosion of the outer bank downstream of the confluence in the Rhone-Lonza confluence (Figure 14) and also with the behavior of the erosion described in the confluence of the Kaskaskia River and Copper Slough [Rhoads et al., 2009].

[61] Coarse sediment supplied by the tributary is mainly transported on the sloping face of the bar by the near-bed flow originating from the main channel. The preferential corridor of coarse sediment transport was found to coincide with the position of the shear layer caused by the junction of both confluent flows. This result is in accordance with the measurements performed by Boyer et al. [2006] where the additional turbulence production in the shear layer is associated to the position of the corridors of sediment transport. In the reported experiment, fine sediment is lifted into suspension by spiral vortices at the downstream corner of the confluence, and transported downstream in a narrow corridor near the inner bank. Segregation of the transported material and outward shifting of the transport corridor of coarse sediment have also been described by Rhoads [1996] and by Rhoads et al. [2009] in a configuration where the tributary is dominant for subcritical flow in both incoming streams.

\section{Conclusions}

[62] This paper examines confluences with relatively low discharge and momentum flux ratios where a small steep tributary with a high supply of poorly sorted sediment joins a large, low-gradient main channel. It reports measurements of the three-dimensional velocity field, turbulence, sediment transport, sediment granulometry and morphology in a laboratory setup and proposes a conceptual model for the hydro-morpho-sedimentary processes in this type of confluence configuration.

[63] A marked bed discordance occurs in the confluence zone, which is mainly determined by the different flow regimes in the main channel and the tributary. The flow depth in the subcritical main channel is considerably higher than in the transcritical steep tributary. This difference in flow depth manifests in a pronounced bed discordance, whereas the water surface elevation only shows minor changes in the confluence zone. Due to this bed discordance, the tributary flow penetrates into the main channel mainly in the upper part of the water column, whereas the mainchannel flow moves beneath the tributary in the lower part of the water column.

[64] Three hydro-morphological interactions provide the increase in sediment transport capacity required to transport the dominant tributary sediment supply through the confluence zone. First, the development of a bar at the inner bank of the downstream channel causes a reduction in the local flow depth, an acceleration of the near-bed flow, and outward deflection of this flow by topographic steering. Second, the bed discordance gives rise to a two-layer flow structure and to three-dimensional flow patterns that are characterized by near-bed cores of high velocity with increased sediment transport capacity. Third, considerable 
turbulence is generated in the shear layer at the junction of the flows originating from the main channel and the tributary. The coincidence of the shear layer with the location of preferential corridors of coarse sediment transport indicates that the increased turbulence levels contribute substantially to the required increase in sediment transport capacity.

[65] The sediment transfer between the tributary and the postconfluence channels mainly occurs near the downstream junction corner of the confluence due to the formation of a stagnation zone at the upstream junction corner that causes an asymmetric distribution of the flow and sediment transport. Sediment provided by the tributary to the postconfluence channel is mainly transported by the near-bed flow originating from the main channel. This near-bed flow has a component that is directed up the slope of the bar. The interplay between the near-bed flow and the downslope gravitational forces on the sediment particles conditions the slope of the bar and causes sediment sorting. Moreover, this near-bed flow prevents the formation of a zone of flow recirculation and deposition of fine sediment at the inner-bank.

[66] This conceptual model is complementary to conceptual models of Best [1988], Boyer et al. [2006] and Rhoads et al. [2009] for confluences with different characteristics. Some similar processes are observed in other asymmetrical confluences with dominant sediment supply by the tributary, but with higher discharge and momentum ratios and mild to moderate bed discordance: (1) the overall outward deflection of the flow by the lateral tributary input that leads to a pronounced asymmetry of the cross-section downstream of the confluence with bar development downstream of the junction corner and the deepest part of the cross-section toward the outer bank; (2) the formation of a stagnation zone at the upstream junction corner that causes the tributary's flow and sediment to enter the main channel toward the downstream junction corner of the confluence; (3) pathways and sorting of coarse sediment on the bar face and pathways of fine sediment confined near the inner bank along the top of the bar. Differences from previous conceptual models are mainly induced by the pronounced bed discordance that restricts the tributary inflow to the upper part of the water column, in contrast to configurations with mild and moderate bed discordance where the tributary inflow occurs over the full water column. As a result, the vertical shear layer that forms at the junction of the tributary and main channel flows is also restricted to the upper part of the water column, and an additional horizontal shear layer is formed where the transverse tributary inflow in the upper part of the water column moves over the longitudinal main-channel inflow in the lower part of the water column. The main channel flow in the lower part of the water column moves up the bar downstream of the confluence junction corner, and prevents the formation of the flow recirculation zone on that bar which is typical for configurations with mild or moderate bed discordance.

[67] Acknowledgments. The research was supported by the Swiss Federal Office for the Environment (FOEN) in the framework of the project "Integrated management of river systems." The second author was partially funded by the Chinese Academy of Sciences fellowship for young international scientists under grant 2009YA1-2 and by the Sino-Swiss science and technology cooperation for joint research, project GJH20908. The authors acknowledge M. Church, A. Densmore, J. Pitlick, B. L. Rhoads, S. Rice, and an anonymous reviewer for constructive comments that helped to improve the manuscript.

\section{References}

Ashmore, P., and G. Parker (1983), Confluence scour in coarse braided streams, Water Resour. Res., 19, 392-402, doi:10.1029/WR019i002p00392.

Best, J. L. (1987), Flow dynamics at river channel confluences: Implications for sediment transport and bed morphology, in Recent Developments in Fluvial Sedimentology, Spec. Publ. SEPM Soc. Sediment. Geol., 39, 27-35.

Best, J. L. (1988), Sediment transport and bed morphology at river channel confluences, Sedimentology, 35, 481-498, doi:10.1111/j.1365-3091.1988. tb00999.x.

Best, J. L., and I. Reid (1984), Separation zone at open-channel junctions, J. Hydraul. Eng., 110, 1588-1594, doi:10.1061/(ASCE)0733-9429(1984) 110:11(1588).

Best, J. L., and A. G. Roy (1991), Mixing-layer distortion at the confluence of channels of different depth, Nature, 350, 411-413, doi:10.1038/ $350411 \mathrm{a} 0$.

Biron, P. M., and S. N. Lane (2008), Modelling hydraulics and sediment transport at river confluences, in River Confluences, Tributaries and the Fluvial Network, edited by S. P. Rice, A. G. Roy, and B. L. Rhoads, pp. 17-43, John Wiley, Hoboken, N. J.

Biron, P., B. De Serres, A. G. Roy, and J. L. Best (1993a), Shear layer turbulence at an unequal depth channel confluence, in Turbulence: Perspectives on Flow and Sediment Transfer, edited by N. Clifford, J. French, and J. Hardisty, pp. 197-213, John Wiley, Chichester, U. K.

Biron, P., A. G. Roy, J. L. Best, and C. J. Boyer (1993b), Bed morphology and sedimentology at the confluence of unequal depth channels, Geomorphology, 8, 115-129, doi:10.1016/0169-555X(93)90032-W.

Biron, P., J. L. Best, and A. G. Roy (1996a), Effects of bed discordance on flow dynamics at open channel confluences, J. Hydraul. Eng., 122, 676-682, doi:10.1061/(ASCE)0733-9429(1996a)122:12(676).

Biron, P., A. G. Roy, and J. L. Best (1996b), Turbulent flow structure at concordant and discordant open-channel confluences, Exp. Fluids, 21, 437-446, doi:10.1007/BF00189046.

Biron, P. M., A. Richer, A. D. Kirkbride, A. G. Roy, and S. Han (2002), Spatial patterns of water surface topography at a river confluence, Earth Surf. Processes Landforms, 27, 913-928, doi:10.1002/esp.359.

Biron, P. M., A. S. Ramamurthy, and S. Han (2004), Three-dimensional numerical modeling of mixing at river confluences, J. Hydraul. Eng., 130, 243-253, doi:10.1061/(ASCE)0733-9429(2004)130:3(243).

Blanckaert, K. (2010), Topographic steering, flow recirculation, velocity redistribution, and bed topography in sharp meander bends, Water Resour. Res., 46, W09506, doi:10.1029/2009WR008303.

Blanckaert, K., and H. J. De Vriend (2004), Secondary flow in sharp open-channel bends, J. Fluid Mech., 498, 353-380, doi:10.1017/ S0022112003006979.

Blanckaert, K., and W. H. Graf (2001), Mean flow and turbulence in openchannel bend, J. Hydraul. Eng., 127, 835-847, doi:10.1061/(ASCE) 0733-9429(2001)127:10(835).

Blanckaert, K., and U. Lemmin (2006), Means of noise reduction in acoustic turbulence measurements, J. Hydraul. Res., 44, 3-17, doi:10.1080/ 00221686.2006 .9521657$.

Blanckaert, K., A. Duarte, and A. J. Schleiss (2010), Influence of shallowness, bank inclination and bank roughness on the variability of flow patterns and boundary shear stress due to secondary currents in straight open-channels, Adv. Water Resour., 33, 1062-1074, doi:10.1016/j. advwatres.2010.06.012.

Boyer, C., A. G. Roy, and J. L. Best (2006), Dynamics of a river channel confluence with discordant beds: Flow turbulence, bed load sediment transport, and bed morphology, J. Geophys. Res., 111, F04007, doi:10.1029/ 2005JF000458.

Bradbrook, K. F., P. M. Biron, S. N. Lane, K. S. Richards, and A. G. Roy (1998), Investigation of controls on secondary circulation in a simple confluence geometry using a three-dimensional numerical model, Hydrol. Processes, 12, 1371-1396, doi:10.1002/(SICI)1099-1085(19980630) 12:8<1371::AID-HYP620>3.0.CO;2-C

Bradbrook, K. F., S. N. Lane, and K. S. Richards (2000a), Numerical simulation of three-dimensional, time-averaged flow structure at river channel confluences, Water Resour. Res., 36, 2731-2746, doi:10.1029/ 2000WR900011.

Bradbrook, K. F., S. N. Lane, K. S. Richards, P. M. Biron, and A. G. Roy (2000b), Large eddy simulation of periodic flow characteristics at river channel confluences, J. Hydraul. Res., 38, 207-215, doi:10.1080/ 00221680009498338

Bradbrook, K. F., S. N. Lane, K. S. Richards, P. M. Biron, and A. G. Roy (2001), Role of bed discordance at asymmetrical river confluences, J. Hydraul. Eng., 127, 351-368, doi:10.1061/(ASCE)0733-9429(2001) 127:5(351).

Chow, V. T. (1959), Open-Channel Hydraulics, 680 pp., McGraw-Hill, Singapore. 
De Serres, B., A. G. Roy, P. M. Biron, and J. L. Best (1999), Threedimensional structure of flow at a confluence of river channels with discordant beds, Geomorphology, 26, 313-335, doi:10.1016/S0169$555 \mathrm{X}(98) 00064-6$

Fujita, I., and S. Komura (1987), Visualization of the flow at a confluence, paper presented at the Third International Symposium on Refined Flow Modeling and Turbulence Measurements, Int. Assoc. of Hydraul. Res., Tokyo, Japan, 26-28 July.

Gaudet, J. M., and A. G. Roy (1995), Effect of bed morphology on flow mixing length at river confluences, Nature, 373, 138-139, doi:10.1038/ $373138 \mathrm{a} 0$.

Hurther, D., and U. Lemmin (1998), A constant-beam-width transducer for 3D acoustic Doppler profile measurements in open-channel flows, Meas. Sci. Technol., 9, 1706-1714, doi:10.1088/0957-0233/9/10/010.

Kantoush, S. A., G. De Cesare, J. L. Boillat, and A. J. Schleiss (2008), Flow field investigation in a rectangular shallow reservoir using UVP, LSPIV and numerical modelling, Flow Meas. Instrum., 19, 139-144, doi:10.1016/j.flowmeasinst.2007.09.005.

Kennedy, B. A. (1984), On Playfair's law of accordant junctions, Earth Surf. Processes Landforms, 9, 153-173, doi:10.1002/esp.3290090207.

Kenworthy, S. T., and B. L. Rhoads (1995), Hydrologic control of spatial patterns of suspended sediment concentration at a stream confluence, J. Hydrol., 168, 251-263, doi:10.1016/0022-1694(94)02644-Q.

Lane, S. N., K. F. Bradbrook, K. S. Richards, P. Biron, and A. G. Roy (2000), Secondary circulation cells in river channel confluences: Measurement artefacts or coherent flow structures?, Hydrol. Processes, 14 2047-2071, doi:10.1002/1099-1085(20000815/30)14:11/12<2047::AIDHYP54>3.0.CO;2-4.

Leclair, S., and A. G. Roy (1997), Variabilité de la morphologie et des structures sédimentaires du lit d'un confluent de cours d'eau discordant en période d'étiage, Géogr. Phys. Quat., 51, 125-139.

Leite Ribeiro, M. (2011), Influence of tributary widening on confluence morphodynamics, $\mathrm{PhD}$ dissertation, 279 pp., Ecole Polytech. Fédérale de Lausanne, Lausanne, Switzerland.

Lemmin, U., and T. Rolland (1997), Acoustic velocity profiler for laboratory and field studies, J. Hydraul. Eng., 123, 1089-1098, doi:10.1061/ (ASCE)0733-9429(1997)123:12(1089).

McLelland, S. J., J. L. Best, and P. J. Ashworth (1996), The origin and downstream development of coherent flow structures at channel junctions, in Coherent Flow Structures in Open Channels, edited by P. J. Ashworth et al., pp. 459-490, John Wiley, Hoboken, N. J.

Mosley, M. (1976), An experimental study of channel confluences, J. Geol., 84, 535, doi:10.1086/628230.

Nezu, I., and H. Nakagawa (1993), Turbulence in open-channel flows, J. Fluid Mech., 269, 373-375, doi:10.1017/S0022112094211618.

Parsons, D. R., J. L. Best, S. N. Lane, O. Orfeo, R. J. Hardy, and R. Kostaschuk (2007), Form roughness and the absence of secondary flow in a large confluence-diffluence, Rio Paraná, Argentina, Earth Surf. Processes Landforms, 32, 155-162, doi:10.1002/esp.1457.

Rhoads, B. L. (1996), Mean structure of transport-effective flows at an asymmetrical confluence when the main stream is dominant, in Coherent Flow Structures in Open Channels: Origins, Scales and Interactions with Sediment Transport and Bed Morphology, edited by P. J. Ashworth et al. pp. 491-517, John Wiley, Hoboken, N. J.

Rhoads, B. L., and S. T. Kenworthy (1995), Flow structure at an asymmetrical stream confluence, Geomorphology, 11, 273-293, doi:10.1016/ 0169-555X(94)00069-4.

Rhoads, B. L., and S. T. Kenworthy (1998), Time-averaged flow structure in the central region of a stream confluence, Earth Surf. Processes
Landforms, $\quad 23, \quad 171-191, \quad$ doi:10.1002/(SICI)1096-9837(199802) 23:2<171::AID-ESP842>3.0.CO;2-T

Rhoads, B. L., and A. N. Sukhodolov (2001), Field investigation of threedimensional flow structure at stream confluences: 1. Thermal mixing and time-averaged velocities, Water Resour. Res., 37, 2393-2410, doi:10.1029/2001WR000316.

Rhoads, B. L., and A. N. Sukhodolov (2004), Spatial and temporal structure of shear layer turbulence at a stream confluence, Water Resour. Res., 40, W06304, doi:10.1029/2003WR002811.

Rhoads, B. L., and A. N. Sukhodolov (2008), Lateral momentum flux and the spatial evolution of flow within a confluence mixing interface, Water Resour. Res., 44, W08440, doi:10.1029/2007WR006634.

Rhoads, B. L., J. D. Riley, and D. R. Mayer (2009), Response of bed morphology and bed material texture to hydrological conditions at an asymmetrical stream confluence, Geomorphology, 109, 161-173, doi:10.1016/j. geomorph.2009.02.029.

Rice, S. (1999), The nature and controls on downstream fining within sedimentary links, J Sediment. Res., 69, 32-39.

Rice, S. P., and M. Church (2001), Longitudinal profiles in simple alluvial systems, Water Resour. Res., 37, 417-426, doi:10.1029/2000WR900266.

Rodríguez, J. F., and M. H. Garcia (2008), Laboratory measurements of 3-D flow patterns and turbulence in straight open channel with rough bed, J. Hydraul. Res., 46, 454-465, doi:10.3826/jhr.2008.2994.

Roy, A. G., and N. Bergeron (1990), Flow and particle paths at a natural river confluence with coarse bed material, Geomorphology, 3, 99-112, doi:10.1016/0169-555X(90)90039-S

Roy, A. G., and R. Roy (1988), Changes in channel size at river confluences with coarse bed material, Earth Surf. Processes Landforms, 13, 77-84, doi:10.1002/esp.3290130110.

Roy, A. G., R. Roy, and N. Bergeron (1988), Hydraulic geometry and changes in flow velocity at a river confluence with coarse bed material, Earth Surf. Processes Landforms, 13, 583-598, doi:10.1002/esp.3290130704.

Roy, A. G., P. M. Biron, T. Buffin-Belanger, and M. Levasseur (1999), Combined visual and quantitative techniques in the study of natural turbulent flows, Water Resour. Res., 35, 871-877, doi:10.1029/ 1998WR900079.

Sekine, M., and G. Parker (1992), Bed-load transport on transverse slope. I, J. Hydraul. Eng., 118, 513-535, doi:10.1061/(ASCE)0733-9429(1992) 118:4(513)

Sukhodolov, A. N., and B. L. Rhoads (2001), Field investigation of threedimensional flow structure at stream confluences: 2. Turbulence, Water Resour. Res., 37, 2411-2424, doi:10.1029/2001WR000317.

Sukhodolov, A., M. Thiele, and H. Bungartz (1998), Turbulence structure in a river reach with sand bed, Water Resour. Res., 34, 1317-1334, doi:10.1029/98WR00269

Tominaga, A., I. Nezu, K. Ezaki, and H. Nakagawa (1989), Three-dimensional turbulent structure in straight open channel flows, J. Hydraul. Res., 27, 149-173, doi:10.1080/00221688909499249.

Weber, L. J., E. D. Schumate, and N. Mawer (2001), Experiments on flow at a $90^{\circ}$ open-channel junction, J. Hydraul. Eng., 127, 340-350, doi:10.1061/(ASCE)0733-9429(2001)127:5(340)

K. Blanckaert, M. Leite Ribeiro, and A. J. Schleiss, Laboratory of Hydraulic Constructions, Ecole Polytechnique Fédérale de Lausanne, Station 18, Lausanne, Vaud CH-1015, Switzerland. (mleiteribeiro@stucky.ch)

A. G. Roy, Faculty of Environment, University of Waterloo, 200 University Ave. W., Waterloo, ON N2L 3G1, Canada. 